\title{
Mesenchymal stem cell therapy assisted by nanotechnology: a possible combinational treatment for brain tumor and central nerve regeneration
}

This article was published in the following Dove Press journal: International Journal of Nanomedicine

\author{
Song Kwon ${ }^{1, *}$ \\ Kwai Han $\mathrm{Yoo}^{2, *}$ \\ Sun Jin Sym ${ }^{2}$ \\ Dongwoo Khang ${ }^{1,3,4}$
}

'Lee Gil Ya Cancer and Diabetes Institute, Gachon University, Incheon 21999, South Korea; ${ }^{2}$ Department of Internal Medicine, Division of Hematology, School of Medicine, Gachon University Gil Medical Center, Incheon, 21565, South Korea; ${ }^{3}$ Department of Gachon Advanced Institute for Health Science \& Technology (Gaihst), Gachon University, Incheon 21999 , South Korea; ${ }^{4}$ Department of Physiology, School of Medicine, Gachon University, Incheon 21999, South Korea

*These authors contributed equally to this work
Correspondence: Dongwoo Khang Department of Physiology, School of Medicine, Gachon University, Incheon 21999, South Korea

Tel +82 $32899 \quad 1525$

Fax $+8232899 \quad 1525$

Email dkhang@gachon.ac.kr

Sun Jin Sym

Division of Hematology and Oncology, School of Medicine, Gachon University and Gil Hospital, Incheon 21565, South Korea

Email sympson@gilhospital.com

\begin{abstract}
Mesenchymal stem cells (MSCs) intrinsically possess unique features that not only help in their migration towards the tumor-rich environment but they also secrete versatile types of secretomes to induce nerve regeneration and analgesic effects at inflammatory sites. As a matter of course, engineering MSCs to enhance their intrinsic abilities is growing in interest in the oncology and regenerative field. However, the concern of possible tumorigenesis of genetically modified MSCs prompted the development of non-viral transfected MSCs armed with nanotechnology for more effective cancer and regenerative treatment. Despite the fact that a large number of successful studies have expanded our current knowledge in tumor-specific targeting, targeting damaged brain site remains enigmatic due to the presence of a blood-brain barrier (BBB). A BBB is a barrier that separates blood from brain, but MSCs with intrinsic features of transmigration across the BBB can efficiently deliver desired drugs to target sites. Importantly, MSCs, when mediated by nanoparticles, can further enhance tumor tropism and can regenerate the damaged neurons in the central nervous system through the promotion of axon growth. This review highlights the homing and nerve regenerative abilities of MSCs in order to provide a better understanding of potential cell therapeutic applications of non-genetically engineered MSCs with the aid of nanotechnology.
\end{abstract}

Keywords: glioblastoma multiforme, tumor inhibition, mesenchymal stem cell, nanocarrier, nerve regeneration, anti-inflammation

\section{Introduction}

The heterogeneity and complexity of tumors make cancer treatment as an ongoing challenge, but the tumor mortality rate has been relatively decreased in recent years due to a better understanding of tumor biology and advance in technology. ${ }^{1}$ Despite the huge progress in cancer treatment, glioblastoma multiforme (GBM), a lethal brain tumor, is still associated with poor prognosis and a median life expectancy of less than fifteen months. ${ }^{2,3}$ Unfortunately, current therapies are not effective against GBM due to the presence of a brain-blood barrier (BBB) and endothelial membranes with high transendothelial electrical resistance located within brain capillaries that tightly regulate paracellular and transcellular perviousness of molecules in the systemic circulation. ${ }^{4,5}$

Since conventional brain tumor chemotherapy exhibits poor tumor brain-blood barrier penetrability, developing new chemotherapies with improved BBB penetrability is important. ${ }^{6}$ For example, despite improved therapeutic nanocarrier 
platform enhances antitumor efficacy, drug delivery to brain is hindered by the poor perviousness through $\mathrm{BBB}^{7}$ In this aspect, stem cell therapy gains great attention to overcome BBB permeability since MSCs can not only cross the BBB but also migrate to target region after transmigrating the BBB for drug delivery.

Mesenchymal stem cells (MSCs) are multipotent cells that can self-renew and differentiate into multiple cell types. ${ }^{8}$ Due to their self-renewal and multilineage differential potential, MSCs are widely used for tissue regeneration and immune disorders. ${ }^{9}$ In addition, significant progress in the understanding of MSC biology has opened up their potential for therapeutic use in brain tumor. ${ }^{8,10}$ The BBB-penetrable ability of MSCs has been explored in order to overcome the barricade of transporting drugs to brain tumor sites, and the multi-differentiating capacity of MSCs has been proposed as a potential solution for regenerative therapy. ${ }^{11-14}$ Transmigration of MSCs across the BBB is facilitated under both physiological and pathophysiological condition.${ }^{15,16}$ In addition, the regenerative potential of MSCs is associated with nerve regeneration and secrete factors that can reduce inflammation. ${ }^{17}$ As such, MSCs have both abilities on tumor tropism and anti-inflammatory property. In clinical aspect, MSCs are also relatively easy to isolate and transplant back into the patients after their propagation. ${ }^{18,19}$ Due to their unique abilities and ease of manipulation, the ability of MSCs can be further enhanced therapeutic efficiencies through genetic engineering, but the potential tumorigenesis induced by viral vectors is a major concern over their clinical application despite the promising results in antitumor treatment using genetically modified stem cells. ${ }^{20}$

In this aspect, non-genetically engineered MSCs assisted by nanoparticles have garnered attention due to their less immunotoxicity compared to that of genetically modified MSCs. ${ }^{21,22,23,24,25}$ Concurrently, nanotechnology has made significant contributions to the field of oncology over the past decades. Various nanocarriers including liposomes, inorganic nanocarriers, and polymeric micelles hold huge nanotherapeutic potential, and these types of nanocarriers have shown promise in clinical practice with several nanotherapeutic platforms such as chemotherapy, hyperthermia, gene therapy, and radiotherapy already being used in clinical practice. ${ }^{26-30} \mathrm{In}$ nanoparticles-assisted stem cell therapy, the homing and apoptosis-inducing properties of MSCs are enhanced using adjuvant drug-loaded and membrane-conjugated nanoparticles. ${ }^{31-}$ ${ }^{33}$ This review will address on the clinical application of MSCs advanced with nanotechnology, specifically, in GBM treatment and post nerve regenerative therapy.

\section{General concept of BBB}

The BBB is a continuous endothelial membrane, placed in brain microvessels, that has tight junctions and maintains its barrier properties by constantly interacting with astrocytes and pericytes (Figure 1). ${ }^{34}$ Both astrocytes and pericytes play vital roles in maintaining the barrier properties of the BBB by providing cellular connections and structural integrity. ${ }^{35,36}$ The BBB is essential not only for sustaining homeostasis of brain microenvironment but also for protecting the neurons from toxins. ${ }^{37}$ The BBB restricts the entry of molecules with a molecular weight greater than 400 Daltons and molecules with hydrophilicity by containing more than 8 hydrogen bonds, whereas certain molecules including molecules with lipophilicity, glucose, oxygen, and carbon dioxide can transverse the BBB mainly via passive diffusion. ${ }^{34,38}$ Carrier-mediated transport and receptor-mediated transport also support the uptake of nutrients, but the BBB can also efflux unwanted molecules from the brain. ${ }^{39}$ The BBB under intact conditions, therefore, prevents the efficient delivery of drugs thereby reducing the drug efficiency. Conversely, alteration of the BBB can worsen neuro-disorders by allowing the entry of neurotoxins, xenobiotics, and pathogens that can induce neuronal damages. ${ }^{40}$ This phenomenon of the BBB rupture is associated with aberrant vascularization in GBM (Figure 1). ${ }^{41}$ Since tumor angiogenesis is inevitable and occurs in response to the oxygen and nutrient requirements of the tumor, the structure of BBB is compromised (Figure 1). ${ }^{41,42}$ The dramatic increase in the number of blood vessels at the tumor microenvironment increases the nanoparticle distribution in tumor tissue more than normal tissue via the enhanced permeability and retention effect. ${ }^{43}$

\section{Brain tumor (GBM)}

GBM is the most common and a malignant form of primary brain tumor in adults. The morbidity and mortality of GBM remain high despite the technological advances in cancer treatment. Prognosis of GBM is poor, with median survival rates of approximately fifteen months. ${ }^{44}$ Conventional treatment for GBM is surgical resection followed by radiotherapy and chemotherapy, but tumor recurrence after surgical removal and therapeutic resistance to radiotherapies and chemotherapies results in the poor prognosis of GBM. $^{45,46,47}$ Therefore, development of a new strategy with improved tumor specificity and reduced normal cell toxicity is required to overcome tumor vitality and for maximizing drug accumulation at tumor sites. ${ }^{48}$ 


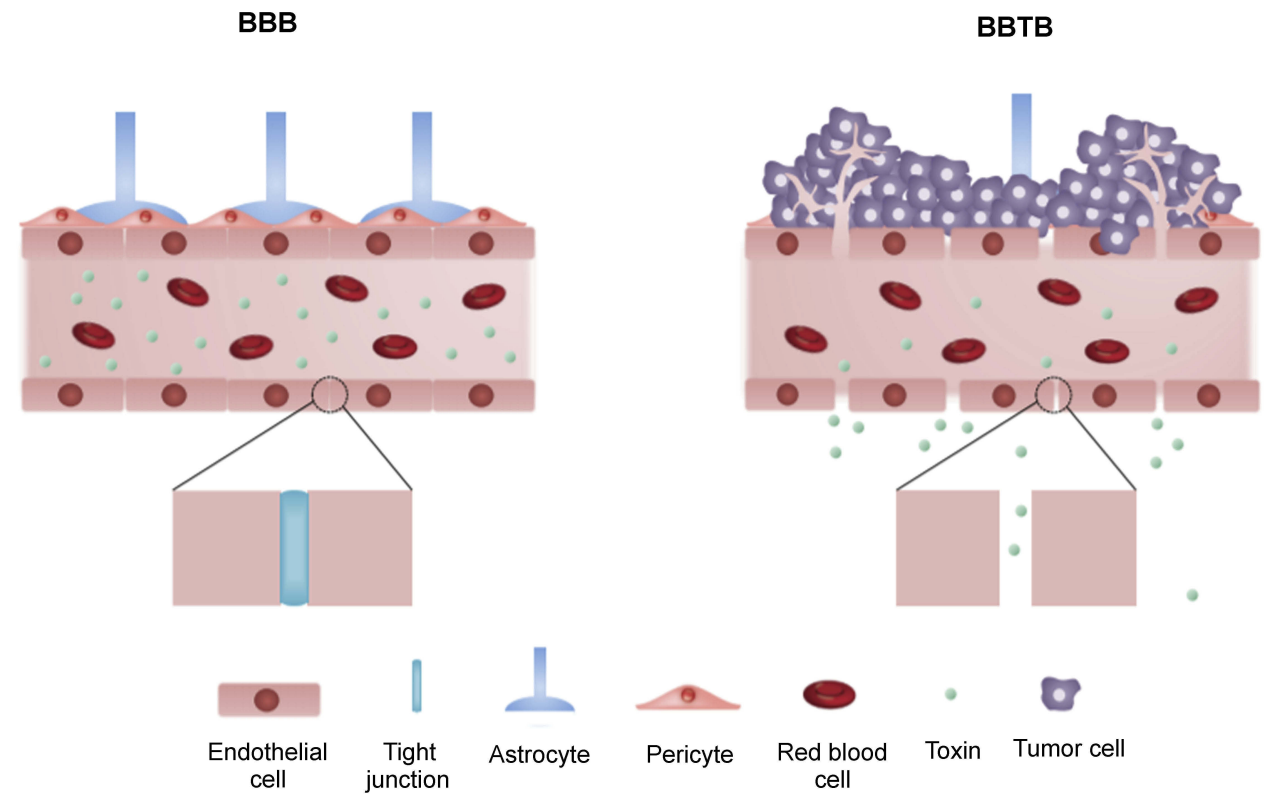

Figure I The structure of blood-brain barrier (BBB) and blood-brain tumor barrier (BBTB). The blood vessels with the intact BBB are enclosed by endothelial cells with tight junction while the tight junction between endothelial cells is disrupted by infiltration of tumor cells in the BBTB.

\section{Brain tumor-induced BBB disruption}

The function and structure of BBB can be disrupted heterogeneously under pathophysiological conditions, and the disruption of BBB can be observed using gadolinium-based MRI contrast agents and immunohistochemistry. ${ }^{49,50,51}$ Heterogeneous alteration of the BBB is initiated by cytokines released from glioma cells and aberrant angiogenesis (Figure 1) ${ }^{52,53}$ In GBM, a large number of glioma cells interact with blood vessels and infiltrate the healthy brain cells. The gradual progression of random neovascularization and growth of glioma cells breakdown the tight junctions of the BBB that can lead the formation of a leaky and heterogeneous nature of $\mathrm{BBB}$, known as the blood-brain tumor barrier (BBTB) (Figure 1). ${ }^{41,53}$ Specifically, the difference in drug permeability is observed in tumor-dense areas and peripheral areas due to distinct tumor microvessel populations and spatial structures of the capillary pores presented in GBM. ${ }^{41}$ Interestingly, uneven permeability induced by abnormal microvessel population has higher gold nanoparticle distributions of $10 \mathrm{~nm}, 50 \mathrm{~nm}$, and 100 $\mathrm{nm}$ diameter in the tumor brain tissue than in normal brain tissue, and $10 \mathrm{~nm}$ gold nanoparticles showed the highest accumulation in the tumor brain tissue compared to bigger sized gold nanoparticles. This phenomenon may contribute to the increased drug delivery when nanodrugs are exposed to leaky structure of the BBB. ${ }^{43}$ Similarly, the increased permeability of the BBTB compared to that of the intact
BBB may potentially result in higher accumulation of migrated MSCs in tumor cells in pathophysiological condition without direct transmigration of BBB.

\section{Conventional radio-, chemo-, and immune cell therapies for treating GBM}

The conventional therapy for patients with GBM requires surgical resection of tumor sites followed by chemotherapy or radiotherapy. However, minimal progress in prognosis has been observed over the past years due to the infiltration of tumor cells inside healthy brain cells. ${ }^{54}$ This heterogeneous nature of tumor cells results in the incomplete removal of tumor cells, and, thus, insufficient tumor resection area greatly increases the probability of tumor recurrence, resulting in a corresponding decline in survival rate. ${ }^{55,56}$ Post-operative chemotherapy or radiotherapy is performed in order to eradicate residual tumor from surgery and increase the survival rate of patients, but chemo- and radioresistance of tumor cells remains a significant hurdle. Conventional radiotherapy with highenergy X-ray induces apoptosis in tumor cells by damaging DNA strands, but the presence of EGFRvIII in tumor cells upregulates the DNA repair system (Figure 2) ${ }^{57}$ Similar to radiotherapy, chemotherapy uses temozolomide, which is an alkylating agent that induces apoptosis by methylating purines, but resisted by $\mathrm{O}^{6}$-methylguanine-DNA methyltransferase (MGMT), an arbitrator of DNA repair. ${ }^{58}$ Higher expression 


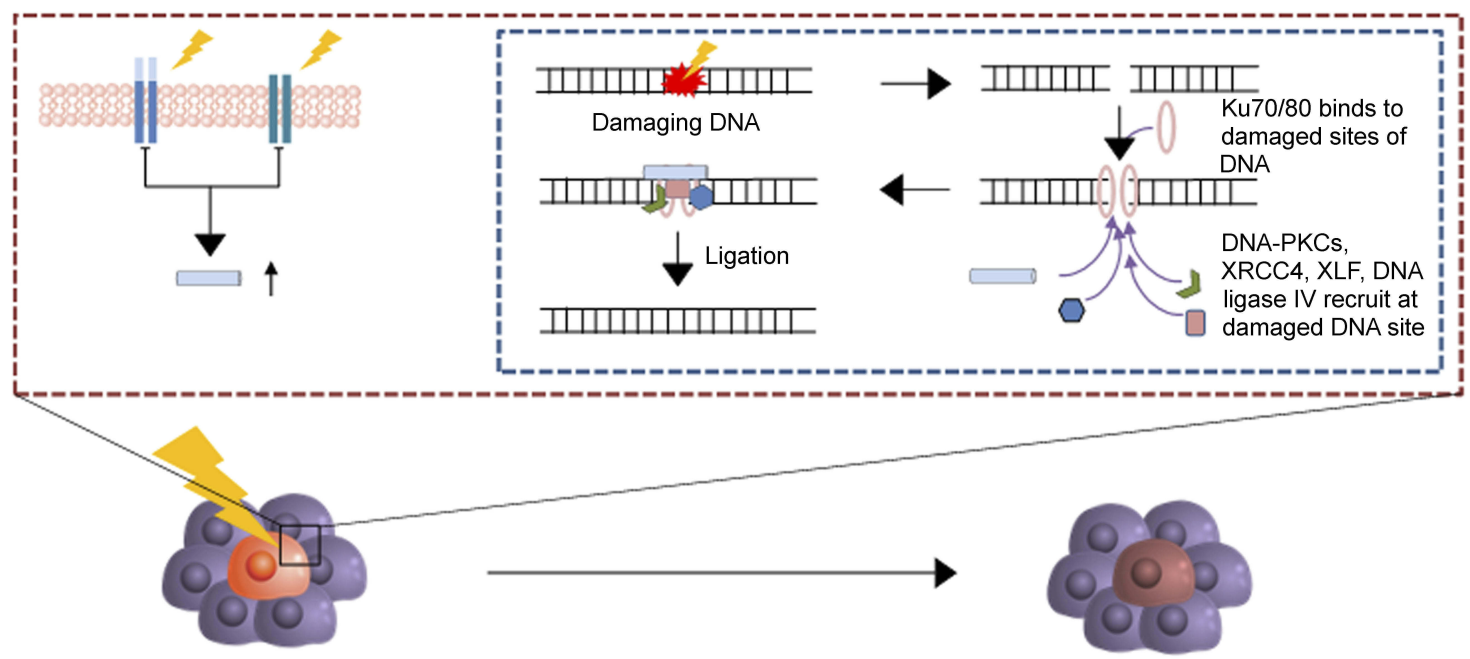

Glioma cell

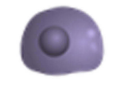

Tumor cell

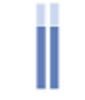

EGFR

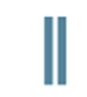

EGFRvIII
Radiation resistance Glioma cell

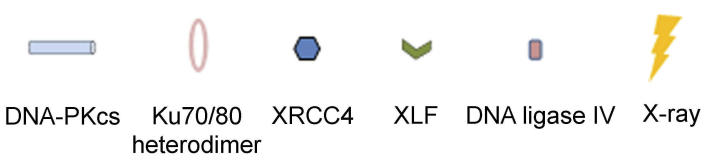

Figure 2 The radiotherapy resistance mechanism in glioma cell. After the break of DNA, Ku70/Ku80 heterodimers bind to damaged ends of DNA and triggers the recruitment of overexpressed DNA-PKcs from EGFRvIll to the damaged DNA ends. Then, XRCC4, DNA ligase IV and XLF subsequently bind to the damaged ends of DNA for the ligation.

of MGMT in tumor cells results in low temozolomide-induced anticancer efficacy. ${ }^{59}$ Furthermore, increased expression of ATP-binding cassette transporters in tumor cells contributes to the chemoresistance of tumor cells due to the efflux of chemotherapeutic agents from tumor cells with multidrug resistance. $^{39,60}$

As of today, aside from radio- and chemotherapy, chimeric antigen receptor $\mathrm{T}$ cell (CAR T-cell) therapy holds great promise in brain tumor treatment. ${ }^{61} \mathrm{CAR}$ T-cell therapy is an immunotherapy that genetically engineers autologous $\mathrm{T}$ cells to express appropriated CAR for the desired antigen. ${ }^{62}$ The primary method of CAR T cells delivery, however, is limited to local administration to circumvent the BBB, a barrier that blocks most of the innate $\mathrm{T}$ cells from entering the brain. ${ }^{62}$ As such, the efficiency of antitumor therapies remains a challenge due to the factors discussed earlier.

\section{Homing of mesenchymal stem cells to cancer cells is acknowledged, but tumor suppression is still controversial}

MSCs are non-hematopoietic stem cells with the ability of self-renewal and multiple-lineage differentiation. MSCs can also recruit at the tumor or inflammatory site for tissue regeneration upon receiving endocrinal signals, such as SDF-1, TNF- $\alpha$, and interleukins from injured tissues. ${ }^{63-65}$ Interestingly, favorability of tumor tropism varies from one MSC lineage to another, such that, for instance, tumor tropism of bone marrow MSCs is the most favorable for lung tumors (A549 and H1975 cells). ${ }^{24}$ Despite their different favorability of tumor tropism, MSCs can migrate to multiple types of tumors, including gliomas, breast, colon, ovarian, lung, and metastatic tumors. ${ }^{63-67}$ Along with inherent tumor tropism, MSCs are relatively easy to isolate, culture, expand, and differentiate in vitro, which makes MSCs as excellent candidates for cell therapy. $^{68,69}$

MSC-mediated suppression of tumor growth was observed in various cancer models such as melanoma (skin cancer), hepatoma (liver tumor), and breast cancer. ${ }^{70-72}$ MSC-mediated tumor inhibition is induced by suppressing angiogenesis, regulating signaling pathways, and promoting apoptosis in the tumor microenvironments. ${ }^{73-76}$ However, the potential clinical application of MSCs is still controversial. Although the unique features of MSCs such as tumorspecific targeting and easy manipulation make MSCs a potential candidate for tumor targeting agent, ${ }^{77}$ the reproduction of the same MSC phenotypes, which is affected by 
various factors including cell density, culture conditions, and passages, must be addressed before future clinical application. ${ }^{78,79}$ Along with the optimization of MSC reproducibility, the tumor progression induced by MSCs is also a hurdle in the clinical application of MSCs. For example, MSCs are known to be associated with a higher degree of metastasis development. ${ }^{80-82}$ When MSCs are co-injected with human breast cancer cells such as MCF-7, MDA MB231, and MDA MB-435, enhanced tumor growth and lung metastases are observed. ${ }^{83}$ Production of CCL5 from MSCs that are stimulated by breast tumor cells promotes breast cancer metastasis. Furthermore, TGF- $\beta 1$ secreted by MSCs suppresses leukocytes proliferation, contributing to the tumor progression. ${ }^{82}$ Due to the integrated tumor suppression and progression effects of MSCs, numerous factors including the types of tumor, heterogeneity, tumor microenvironment, and MSC source need to be thoroughly considered before clinical applications.

\section{Brain tumor tropism by MSCs}

The migration of MSCs to multiple types of tumors, such as gliomas, colon, ovarian, lung, and breast tumors may infer that tumor tropism of MSCs is independent of type of the tumor sites. ${ }^{84,85}$ Regardless of tumor types, endocrinal signals from tumor microenvironment influence the migration of MSCs to tumor sites, and among these signals, CXCR4/SDF-1 is the main signal that regulates the migration of MSCs. ${ }^{86-88}$

Internalizing magnetic iron oxide nanoparticles into MSCs can further enhance the tumor tropism of MSCs. ${ }^{32}$ Previous study showed that the migration process is heavily depended on the interaction between SDF-1 $\alpha$ and CXCR4, and the elevation of CXCR4 levels in MSCs was observed after internalization of magnetic iron oxide nanoparticles and any gene modification. ${ }^{89}$ The increase in CXCR4 levels resulted in improved migration in both traumatic brain injury and glioblastoma models (Figure 3A).

\section{BBB-penetration by MSCs under physiological condition}

Despite technological advances in molecular biology and related fields, the molecular mechanism of tumor tropism by MSCs is still poorly understood. ${ }^{90}$ Recent findings revealed that multiple factors such as chemokines, cytokines, and their receptors (mainly SDF-1/CXCR4 interaction) are involved in the migration of MSCs in vitro. ${ }^{16}$ Furthermore, expression of the $\alpha-4 / \beta-1$ heterodimer, also known as very late antigen-4 (VLA-4), on the cell surface facilitates cell to cell interaction with vascular cell adhesion molecule-1 (VCAM-1) which help in the anchoring MSCs to endothelial cells (Figure 3B). ${ }^{91}$ Similar to the VLA-4 and VCAM-1 interaction, CD44 expressed on the surface of MSCs also mediate the cell to cell interaction with hyaluronic acid receptor in order to strengthen the MSCs anchorage. ${ }^{92}$ As MSCs transmigrate across BBB, matrix metalloproteinases-2 secreted by MSCs regulates the homing ability of MSCs by degrading the extracellular matrix (Figure 3B). ${ }^{93}$

Importantly, the proposed mechanism of MSC migration across the $\mathrm{BBB}$ is relatively similar to that of leukocytes multistep-targeted cascades interacting with endothelial cells (Figure 3B). The leukocyte is a type of blood cell that plays a vital role in the immune system. The presence of BBB also restricts the migration of leukocytes into brain cells, but various studies have reported that during inflammation, leukocytes can traverse the BBB. ${ }^{94}$ The mechanism underlying the transmigration of leukocytes is a series of adhesion and migration process. Leukocytes interact with endothelium through intercellular adhesion molecule-1 and VCAM-1mediated interactions. ${ }^{95}$ Leukocytes then firmly anchor on the surface of the endothelium. Subsequently, leukocytes migrate laterally over the luminal surface. ${ }^{91}$ Then, leukocytes utilize the cytoskeletal protrusions to transmigrate across the BBB via transcellular and paracellular migration. ${ }^{96}$ Molecules expressed by MSCs, including chemokine receptors and cell adhesion molecules, resemble those expressed by leukocytes. MSCs, in a mechanism similar to leukocytes, associate with endothelial cells and transmigrate via paracellular and transcellular processes. However, unlike leukocytes, MSCs do not laterally migrate over the luminal surface. ${ }^{91}$ Rather, MSCs form blebs, a cell surface protrusion with diameter of $1-5 \mu \mathrm{m}$, and interact with endothelial cells to trigger transmigration. ${ }^{97}$

\section{Roles of MSCs in tumor inhibition Cancer apoptotic induction by MSCs}

Although some studies discussed tumor promotion induced by MSCs, MSCs can promote apoptosis of tumor cells by regulating apoptotic signaling pathways. The inhibitory effects of murine-derived MSCs on hepatoma H22 (murine hepatic carcinoma cells) and insulinoma INS-1 (murine pancreatic carcinoma cells) cell lines were heavily influenced by the upregulation of $\mathrm{p} 21$, which is a downregulator of cell cycle and apoptosis-associated caspase- 3 pathway in 


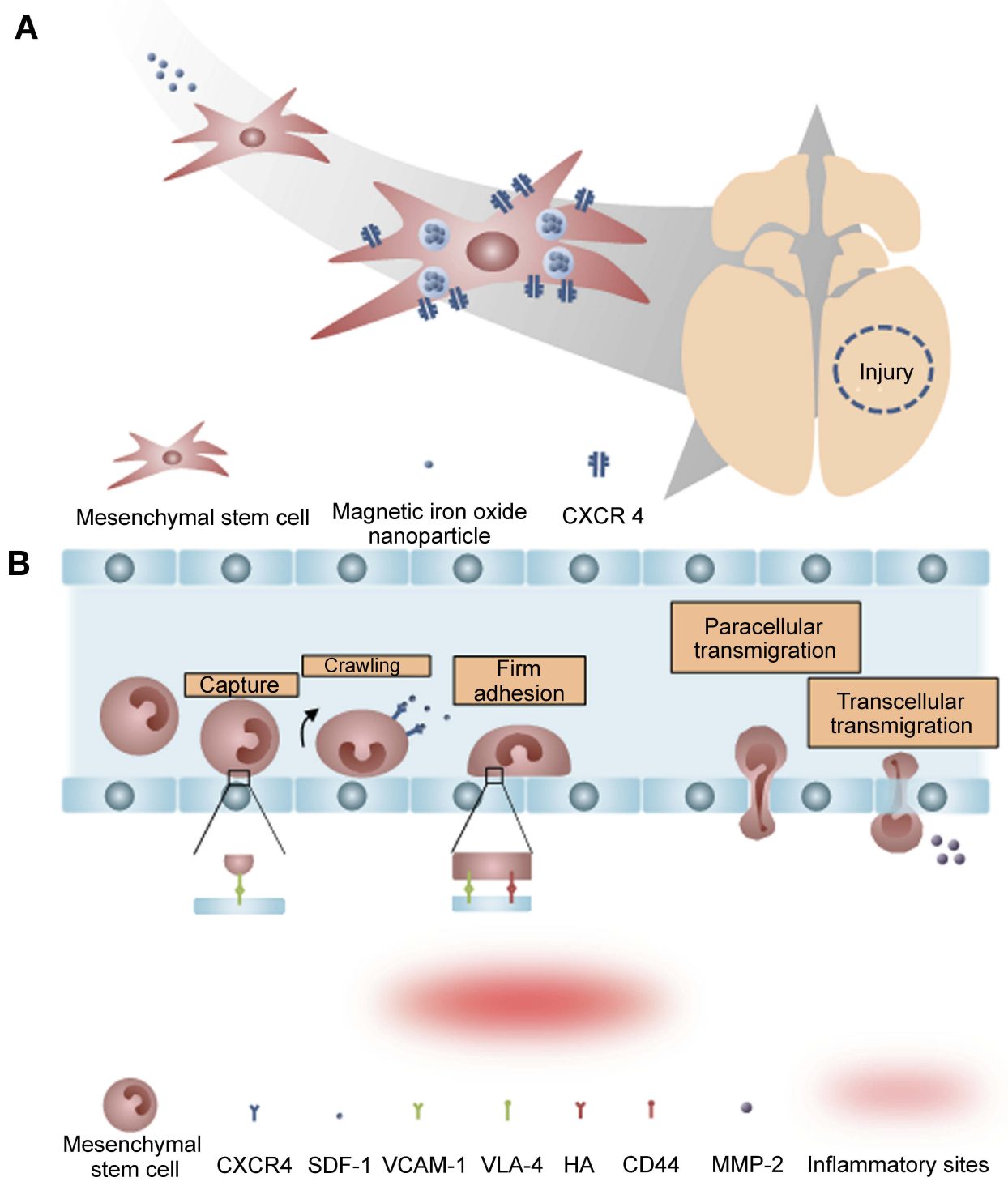

Figure 3 The tumor tropism of mesenchymal stem cells (MSCs). (A) Schematic illustration of tumor tropism of CXCR4-overexpressed MSCs (B) Homing mechanism of MSCs to tumor sites.

a direct co-culture condition. ${ }^{98}$ This phenomenon further suggests the tumor suppressive efficacy of MSCs by cancer apoptosis stimulation through $\mathrm{G}_{0} / \mathrm{G}_{1}$ phase arrest regardless of host immunosuppression. ${ }^{74}$ Factors released from MSCs induce apoptosis in tumor cells through triggering various apoptosis signaling pathways. ${ }^{70,99,100}$ Similar to the direct co-culture condition, the MSC conditioned media exhibits inhibitory effects on melanoma cell growth via $\mathrm{G}_{0} / \mathrm{G}_{1}$ phase arrest and caspase-3/7 pathway activation. ${ }^{70}$ Consistent with these results, hUCBSC (human umbilical cord blood mesenchymal stem cells) downregulates the X-linked inhibitor of apoptosis protein (XIAP), and, consequently, induces apoptosis in glioma cells through the activation of caspase-3/9 pathways. ${ }^{99}$ Conditioned MSC media alone also can downregulate XIAP and survivin genes, which in turn, results in the upregulation of caspase-3/9 genes in glioma cell lines. ${ }^{100}$

Although MSCs alone can induce apoptosis in tumor cells by regulating signaling pathways, apoptotic induction of MSCs can be improved by triggering the overexpression of tumor necrosis factor related apoptosis-inducing ligand (TRAIL) in MSCs through the internalization of amino group-end poly ( $\beta$-amino esters) based nanoparticles. ${ }^{101}$ Non-virally overexpressed TRAIL on 
the surface of MSCs interacts with DR4 and DR5 receptors and induces apoptosis by activating the caspase- 8 pathway in glioblastoma-xenograft models and sarcoma models. ${ }^{101,102}$

\section{Inhibition of cancer angiogenesis by MSCs}

MSCs can not only induce apoptosis of tumor cells but also inhibit angiogenesis through the interaction with endothelial cells to stop nutrient supply of tumor cells. A study discussed that high dosages of MSCs inhibit the development of vasculature by producing reactive oxygen species (ROS), whereas low dosages of MSCs can promote tumor angiogenesis by secreting proangiogenic factors and differentiating into pericytes. ${ }^{100}$ Exposing endothelial cells (EC) to high concentration of MSCs prompts the formation of connexin-43-containing gap junction channels. ${ }^{103}$ MSCs-EC gap junctional communication induces the apoptosis of EC, leading to capillary degeneration. ${ }^{104}$ Another study details the dysfunction of vascularization and reduction in tumor size in GBM tumor xenograft models after systemic injection of MSCs. ${ }^{105}$ MSCs-mediated downregulation of proangiogenic factors is the mechanism underlying the suppression of vascularization in glioma cells. MSCs, when co-cultured with glioma cells, release antiangiogenic factors that downregulate levels of PDGF-BB and IL-1 $\beta$, which result in the reduction of microvessel density (Figure 4A-C). ${ }^{106}$

\section{Antitumor efficacy of oncolytic virus- loaded MSCs}

The inherent nature of MSCs to migrate to tumor sites prompted the development of nanodrug-assisted stem cell therapy. MSCs can not only migrate to tumor sites but also infiltrate into the heterogeneous structure of tumor cells. ${ }^{107,108}$ Thus, utilizing MSCs to deliver chemotherapeutic drugs and vectors into tumor microenvironment may enhance antitumor therapy. Various studies have investigated the potential clinical use of nanocarriers. ${ }^{109-113}$

Internalizing oncolytic virus to MSCs has been widely investigated as a method for safe delivery to target sites. Oncolytic viruses are genetically modified viruses that selectively replicate within tumor cells. ${ }^{114}$ Viral infections by oncolytic virus to cancer cells induce lysis of tumor cells in situ and release viral particles into the neighboring tumor cells, those resulting in more viral infections. Similar to infectious disease, new candidates of tumor cells will subsequently spread viruses throughout their surroundings and completely eradicate the entire tumor after countless rounds of infections. ${ }^{115}$ However, the major hurdle behind oncolytic virus treatment is limited in cell delivery system. ${ }^{116}$ Although intratumoral injection is the primary method for delivering oncolytic viruses, a considerable amount is lost due to backflow of the solution during intratumorally injected. Furthermore, the intravenous injection of oncolytic virus is not preferred since the immune system hinders the delivery of oncolytic virus to target sites. ${ }^{117}$ Thus, most of the oncolytic virus systematically administered is either removed by macrophage phagocytosis or stored in the spleen and liver by mononuclear phagocytes. Therefore, internalization of oncolytic viruses into MSCs only allows for intravenous injection and safe migration toward tumor cells (Figure 5). ${ }^{118}$ Due to the rising interests in the internalization of oncolytic virus, various studies have explored the efficacies of oncolytic virus-loaded MSCs. ${ }^{118,119}$ With regards to brain tumor, oncolytic virus-loaded MSCs showed antitumor efficacy in U87MG xenograft models. ${ }^{118}$ Similar to internalizing oncolytic virus into MSCs, loading or conjugating nanoparticles to MSCs can help in the accumulation of nanoparticles at tumor sites and will be discussed in the next section.

\section{Antitumor efficacy of non-genetically engineered MSCs conjugated with nanodrug}

Genetic alternations of MSCs were extensively investigated for their potential therapeutic effects. ${ }^{120-122}$ For instance, TRAIL-secreting MSCs can effectively inhibit brain tumor by directly binding to the TRAIL-death receptor (DR4 and DR5) on the membrane of tumor cells. ${ }^{123,124}$ Genetically engineered MSCs can not only induce apoptotic signals of brain tumor cells but also can secrete pro-inflammatory cytokines (IL-18 and IL-12) to promote cytotoxic T cell activity. ${ }^{120,125}$ MSCs can also transduce with prodrugs or enzymes as an alternative method for inducing cytokines secreted from MSCs. One of the most popular enzymes or prodrugs is herpes simplex virus type I thymidine kinase (HSV-TK). MSCs-expressing HSV-TK can induce apoptosis of brain tumor cells through the activation of the caspase pathway. ${ }^{126}$ Despite their promising results in brain tumor inhibition, potential tumorigenesis of genetically modified MSCs is a major hurdle to clinical application, so antitumor efficacy without genetic alternation draws attention as an alternative strategy. ${ }^{20}$

Despite the advances in nanoparticle delivery system, using nanoparticles in animal models has been challenging 
A

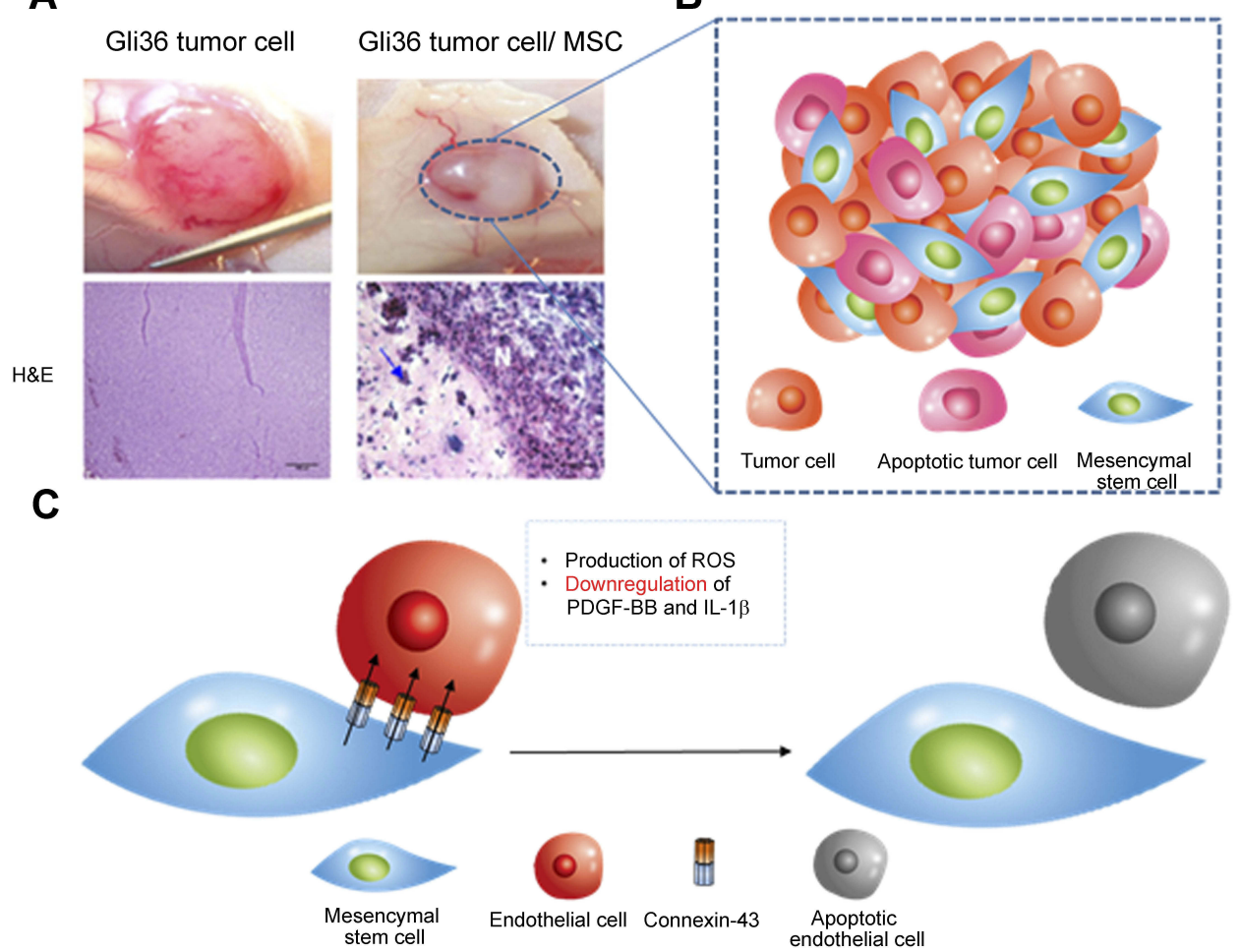

Figure 4 Tumor anti-angiogenesis induced by mesenchymal stem cell (MSC). (A) The gross image and histological analysis of Gil36 and Gil36/MSC co-cultured tumor section (B) Scheme of anti-angiogenesis of MSC when co-cultured with Gli36 cell (C) Schematic figure of capillary degeneration induced by connexin-43 gap junctional channel between MSC and endothelial cell. Reproduced from Ho IA, Toh HC, Ng WH, et al. Human bone marrow-derived mesenchymal stem cells suppress human glioma growth through inhibition of angiogenesis. Stem Cells. 2013;3I(I):I46-155, with permission from John Wiley and Sons. ${ }^{106}$

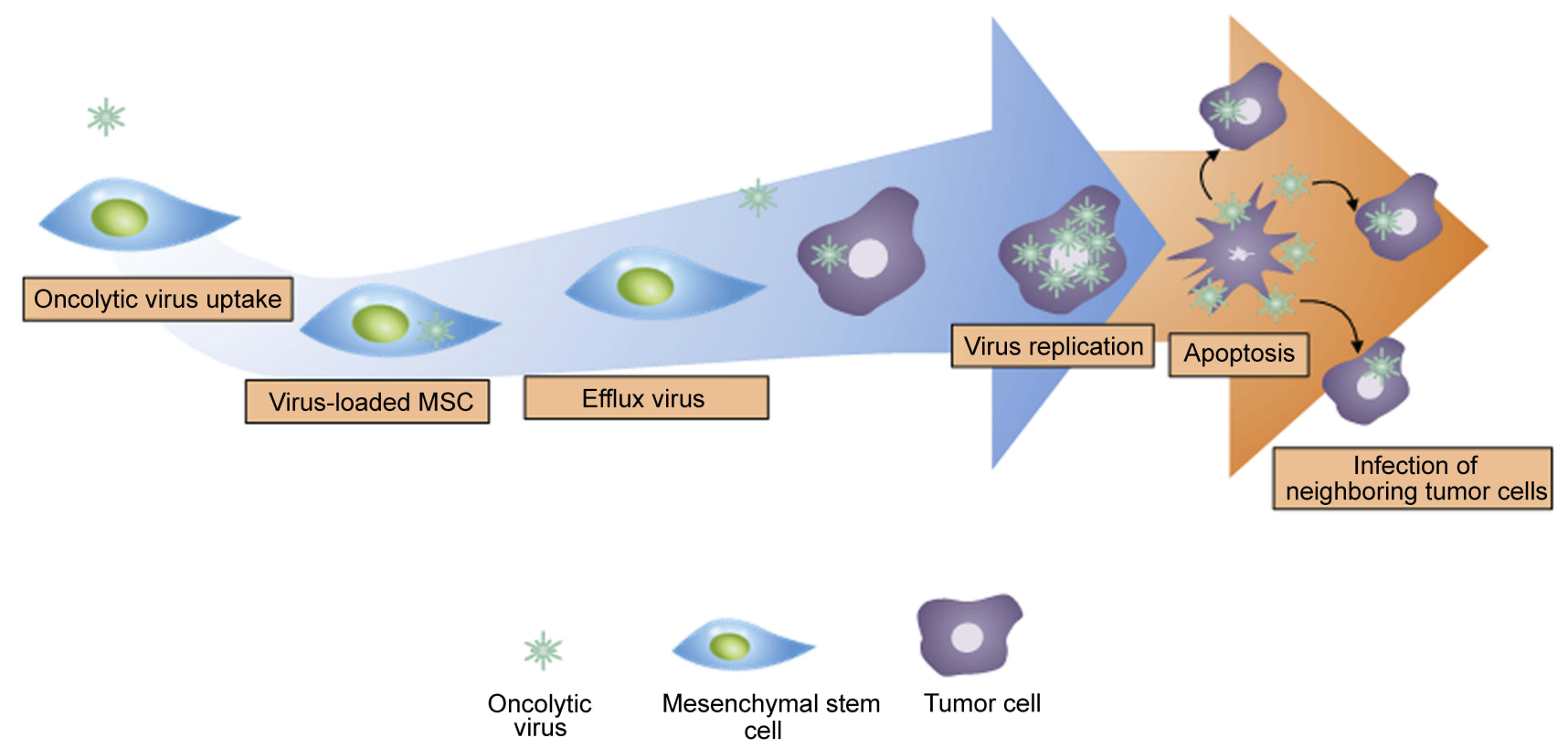

Figure 5 The mechanism of oncolytic virus-loaded mesenchymal stem cell therapy. Replication of oncolytic virus in healthy cells is inhibited and is induced in tumor cells. The rapid replication of oncolytic virus in tumor cells triggers the apoptosis of tumor cells and infects neighboring tumor cells.

due to their inefficient accumulation in tumor sites. One of the most promising approaches in resolving this problem is to use MSCs as carriers. ${ }^{13,127}$ Internalization or conjugation of therapeutics-loaded nanoparticles to MSCs can increase therapeutic efficacy by actively delivering them to the tumor microenvironment. ${ }^{22,32,113}$ For example, 
promising antitumor efficacy was achieved when a brain tumor is treated with paclitaxel-poly (lactic-co-glycolic acid) nanoparticle-loaded MSCs due to the sustained release of the encapsulated paclitaxel to the tumor microenvironment. ${ }^{33}$ Another study demonstrated that silica nanorattle-doxorubicin conjugated MSC when intratumorally administered exhibited delivery of doxorubicin with greater tumor-dispersed distribution and extended the retention time than that of silica nanorattle-doxorubicin in U251 xenograft model but reduced migration ability was observed on MSC. $^{22}$ However, nanodrug-conjugated MSCs exhibited strong lung tumor tropism compared to that of MSCs and succeeded in deep lung tumor model without ruining migration ability (Figure 6A-C). ${ }^{24}$ The tumor homing ability of MSCs is accompanied by conjugated CDs, surface proteins, since conjugation of specific CD to MSCs greatly reduced homing ability such as CD73 while negligible difference in homing ability was observed when conjugation of CD90 to MSCs. ${ }^{24}$ Thus, types of CD that conjugated to MSCs need to be selected carefully to sustain homing ability to cancer cells.

The concept of nanoparticles-loaded MSCs includes $\mathrm{pH}$ sensitive gold nanoparticles internalized by MSCs for the treatment of photothermal therapy. ${ }^{112}$ Internalizing phototherapeutic agents into MSCs did not reduce tumor tropism feature of MSCs and photothermal conversion efficiency.

Despite studies exploring brain homing effects and antitumor efficacies of MSCs, antitumor efficacy of nanoparticlesloaded MSCs on brain tumor model, unfortunately, has not been studied, but only on brain tumor xenograft model. ${ }^{128-130}$ This platform may establish the potential clinical use of MSCs as a nanodrug carrier by observing enhanced antitumor efficiencies of nanodrug-loaded MSCs. The recent development of nanomedicine has led to the emergence of a new drug delivery system, which enables to load versatile types of therapeutic agents onto appropriable nanocarriers.

\section{Correlation of central nerve regeneration and inflammation reduction by MSCs}

Axonal damage is commonly observed in the central nervous system injury. ${ }^{131}$ Axon degeneration is stimulated by several factors: energy depletion for neuron, calciummediated apoptosis, myelin-associated inhibitors. ${ }^{131}$ However, unlike regeneration of the peripheral nervous system, regeneration of the central nervous system is inhibited by two main sources: glial scar and myelin. In the central nervous system, glial cells are essential for immune function in responses to inflammation, ${ }^{132}$ and when damaged, glial scars are formed. Glial scars consist of reactive astrocytes, extracellular matrix (ECM) molecules, chondroitin sulfate proteoglycans, and macrophages and are responsible for protecting damaged neurons and reconstructing the blood-brain barrier. ${ }^{133}$ Despite its benefits, the glial scar prevents axon growth by creating a mechanical barrier and inhibiting molecules. ${ }^{134}$ Similar to glial scar, myelin also inhibits axon regeneration by producing myelin-associated inhibitors such as Nogo and MAG (myelin-associated glycoprotein). ${ }^{135}$

Interestingly, recent studies found that secretomes such as growth factors, cytokines, and antioxidants released from MSCs recruited at inflammatory sites can not only provide analgesic effects in neuropathic models but also promote central nerve regeneration of damaged nerve cells. ${ }^{136}$

Nevertheless, caution is required in activating M2 macrophage for nerve regenerative and anti-inflammatory effect after the tumor eradication since activation of M2 macrophage can not only trigger nerve regeneration but also stimulate tumor growth through the release of IL-4 and IL-13. ${ }^{137}$ Phenotypes of M2 macrophage can be subdivided into M2a, M2b, M2c, and M2d phenotypes, and unlike other phenotypes, M2d phenotype is classified as tumor-associated macrophage (TAM). ${ }^{138}$ Importantly, all these phenotypes participate in pro-tumorigenesis. ${ }^{139}$ All phenotypes of M2 macrophage except M2d phenotype promote tumorigenesis by secreting anti-inflammatory cytokines including IL-10 and IL-1RA to inhibit cytotoxic T cell activity. ${ }^{140,141}$ Similar to other phenotypes of M2 macrophage, M2d phenotype, TAM, enhances tumor growth by promoting the activity of regulatory $\mathrm{T}$ cells and inhibiting dendritic cell maturation through the secretion of IL-10 and TGF- $\beta 1$. TAMs also express PD-L1 on the surface to further suppress immune responses of $\mathrm{T}$ cells. $^{142}$ Understanding of M2 polarization and tumor microenvironment is essential when developing MSCs secretomes for clinical translation.

\section{Anti-inflammation by MSCs can promote regeneration of central nerve system}

Although applications of MSCs were originally focused on the regeneration of damaged tissues, recent studies have discovered the analgesic effects accompanied by inflammation response from MSCs. ${ }^{17,136}$ Among various methods in suppressing inflammatory sites, MSCs 
A

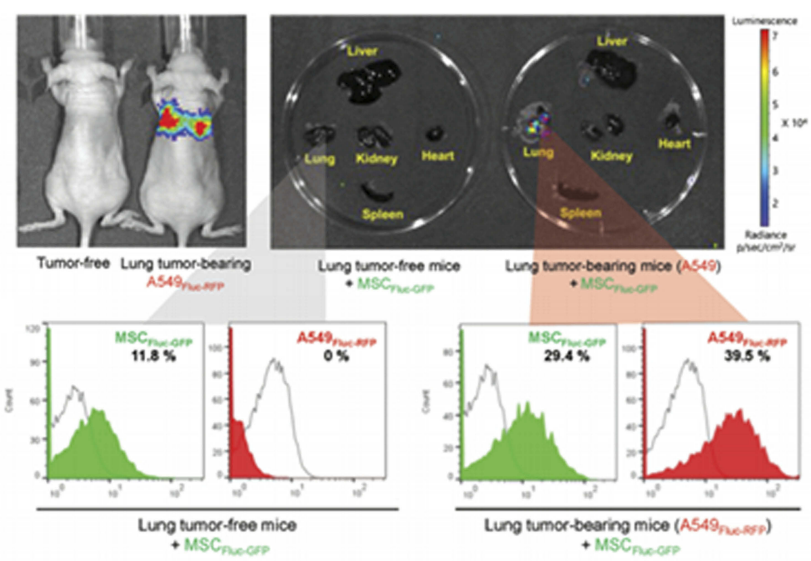

B

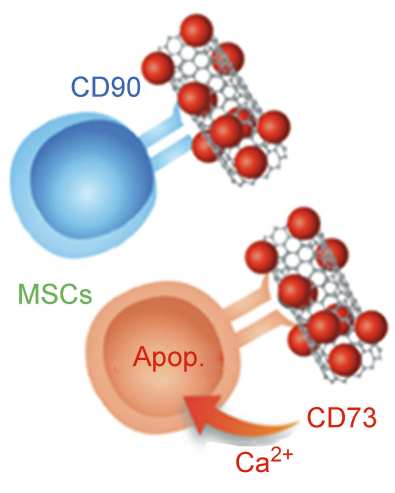

C

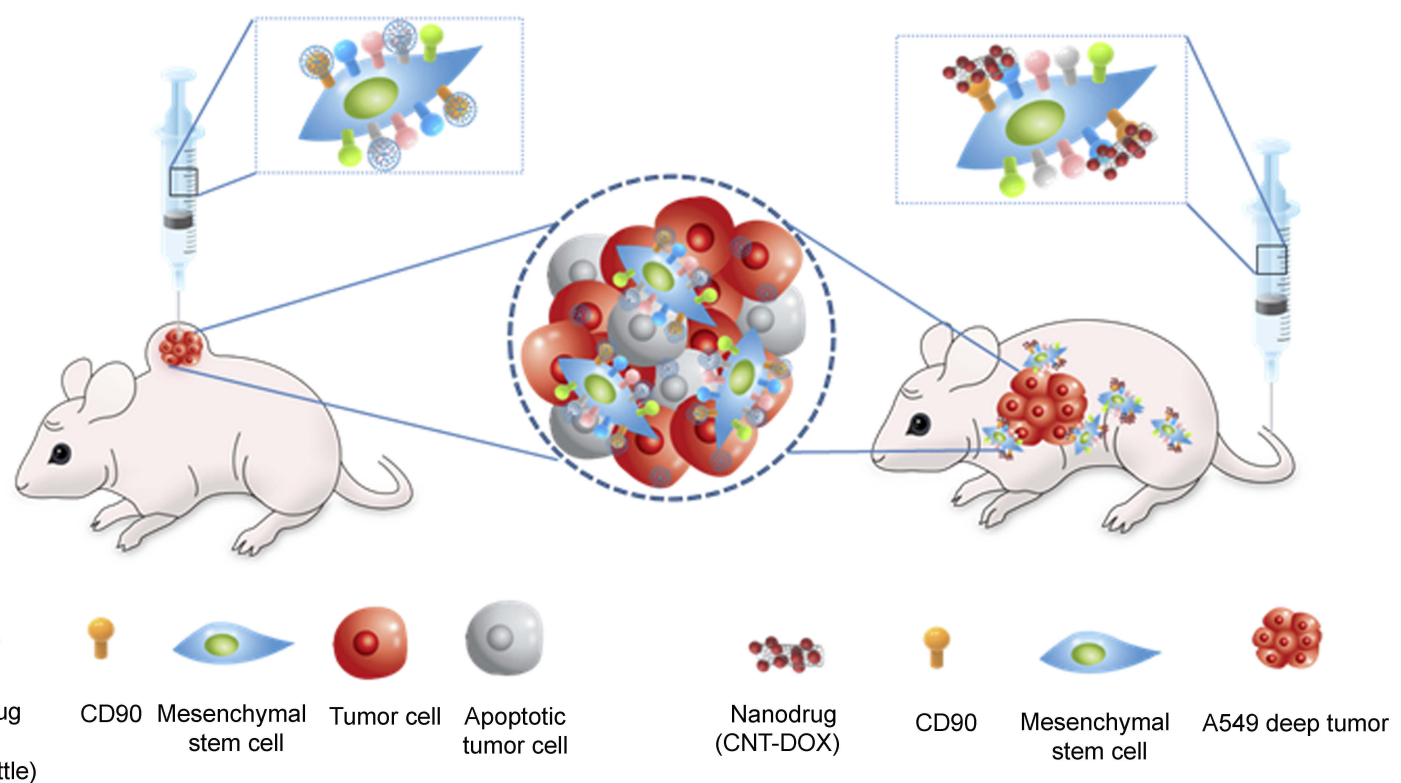

Figure 6 Mesenchymal stem cell (MSC) as a chemotherapeutic carrier. (A) Lung tumor homing ability of MSCs (B) Schematic figure of CD73 or CD90 conjugation to MSCs (C) Schematic figure of silica nanorattle conjugated MSC in xenograft model and nanodrug conjugated MSC for A549 deep tumor treatment. Reproduced from Kim SW, Lee YK, Hong JH, et al. Mutual destruction of deep lung tumor tissues by nanodrug-conjugated stealth mesenchymal stem cells. Adv Sci (Weinh). 20I8;5(5): I700860. ${ }^{24}$

mainly regulate the inflammatory process by releasing anti-inflammatory cytokines to trigger appropriate macrophage polarization. ${ }^{143}$ In this aspect, macrophages are an essential component in immune responses and their fates controlled by MSCs. Specifically, classically activated (M1) macrophage is widely known as a proinflammatory macrophage that can inhibit tumor cells and pathogens while alternatively activated (M2) macrophage is an anti-inflammatory macrophage which is associated with tumor growth as well as tissue repair. ${ }^{144}$ Due to their plasticity in monocyte-macrophage polarization, macrophages can switch between activation states in response to pathological conditions, and when monocytes for M2 macrophage differentiation are promoted, the process of monocyte polarization to M1 macrophage is inhibited. ${ }^{145,146}$ Importantly, MSCs can control monocytes polarization into either M1 macrophages or M2 macrophages by secreting appropriate cytokines in response to pathophysiological condition (Figure 7).

In particular, MSCs can induce anti-inflammatory effects by programing monocytes to polarize into M2 macrophage by releasing cytokines. ${ }^{147}$ In adequate pro-inflammatory states, MSCs produce immunosuppressive factors such as IL-4, IL-6, IL-10, IDO, PGE-2, and TGF- $\beta 1$, in a manner similar to the complex cascades of immunomodulationrelated mechanism. ${ }^{92,148,149}$ These anti-inflammatory cytokines direct monocytes to differentiate into M2 macrophage, which further suppresses immune response by subsequently triggering regulatory $\mathrm{T}$ cell proliferation (Figure 7). ${ }^{150}$ 


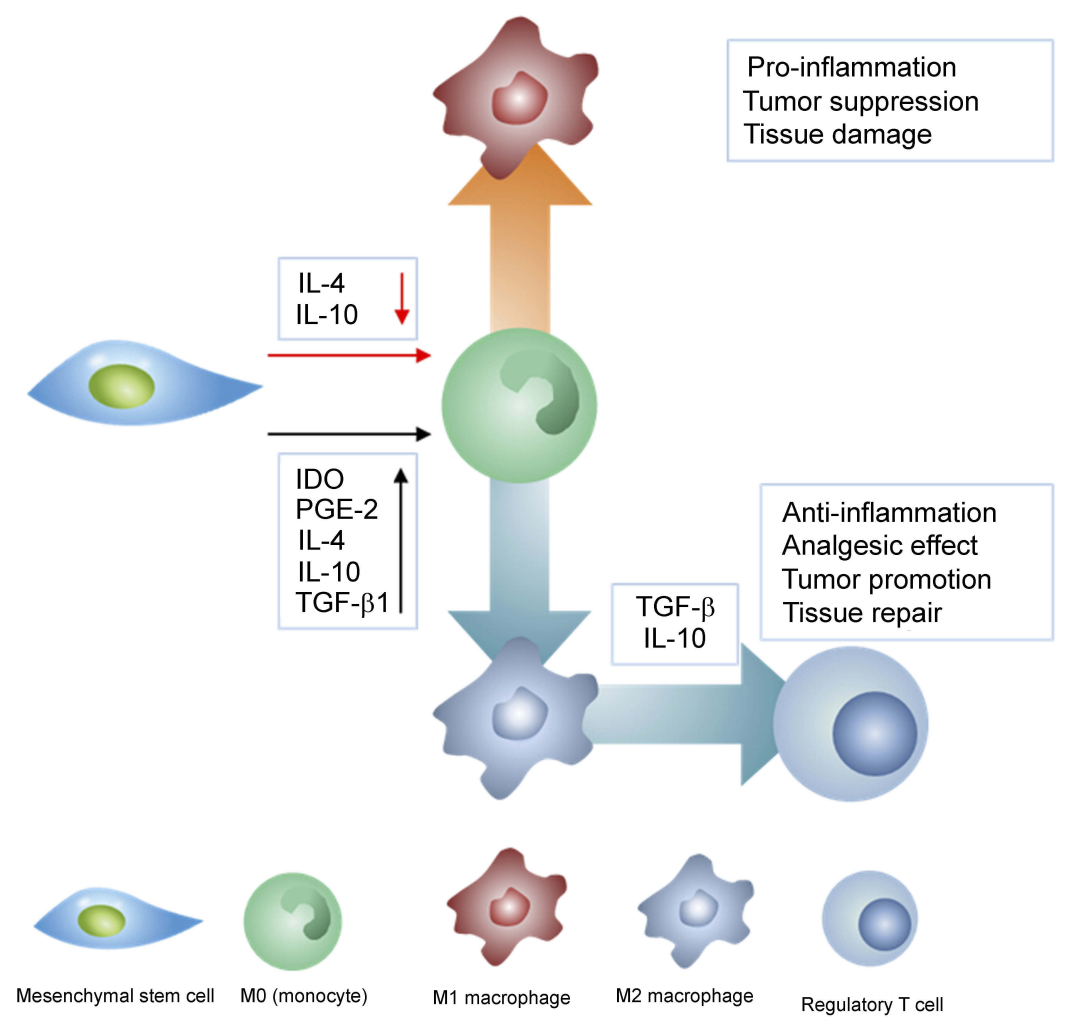

Figure 7 The anti-inflammatory mechanism of mesenchymal stem cells (MSCs). Anti-inflammatory cytokines released from MSCs suppress MI polarization while induce M2 polarization. M2 polarization subsequently triggers the proliferation of regulatory $T$ cells. The red arrow represents suppression while black arrow refers to promotion of the process.

Among these anti-inflammatory cytokines, TGF- $\beta 1$ also plays a crucial role in regulating proliferation of neural and glial cells and regulating analgesic effect. ${ }^{151,152}$ TGF- $\beta 1$ can not only mediate neuropathic pain through pleiotropic effects but also suppress neuropathic pain upon intrathecal injection of MSCs. ${ }^{136}$ Apart from anti-inflammation, these antiinflammatory cytokines including TGF- $\beta 1$, IL-4, and IL-10 can also promote neurite outgrowth in the central nervous system, and, regulatory $\mathrm{T}$ cells promoted by M2 macrophages can support myelin regeneration in the central nervous system. ${ }^{153,154}$ As such, MSCs can not only secrete anti-inflammatory cytokines but also secrete neurotrophic factors to support nerve regeneration.

In addition, various studies have shown that administration of MSCs derived from bone marrow, adipose tissues, and umbilical cord can regenerate peripheral nerve tissues. ${ }^{155,156}$ Intravenously administered MSCs lead to downregulation of inflammation and upregulation of axonal regeneration, while local injection of MSCs can regenerate peripheral nerve tissue. However, the potential therapeutic use of MSCs in central nerve regeneration is still controversial. Although MSCs can differentiate into neuron-like cells with neuronal markers under specific conditions, MSCs-derived neuron cells cannot communicate with each other. ${ }^{157-161}$ However, various studies have reported the positive results of MSCs-promoted neurogenesis. ${ }^{162-164}$ The study of the improved neurological state in a brain hypoxic-ischemic injury model after intravenous administration of adipose-derived MSCderived conditioned media suggests that neural differentiation of MSCs does not contribute to neurological improvement, rather secretomes released from nongenetically modified MSCs result in improvement after neurological damage. ${ }^{163}$ When MSCs reach the inflammatory sites, they secrete pro-survival factors, which include brain-derived neurotrophic factor (BDNF), vascular endothelial growth factor, fibroblast growth factor-2 (FGF-2), and nerve growth factor (NGF) in order to increase survival rates and for axonal regeneration of damaged neurons (Figure 8). ${ }^{162-164}$ Likewise, viral transfection of MSCs through intrastriatal, intracerebral, and intrathecal injections further enhances the delivery of neurotrophic factors that can support axonal growth and decrease apoptosis of damaged neurons. ${ }^{165-167}$ 


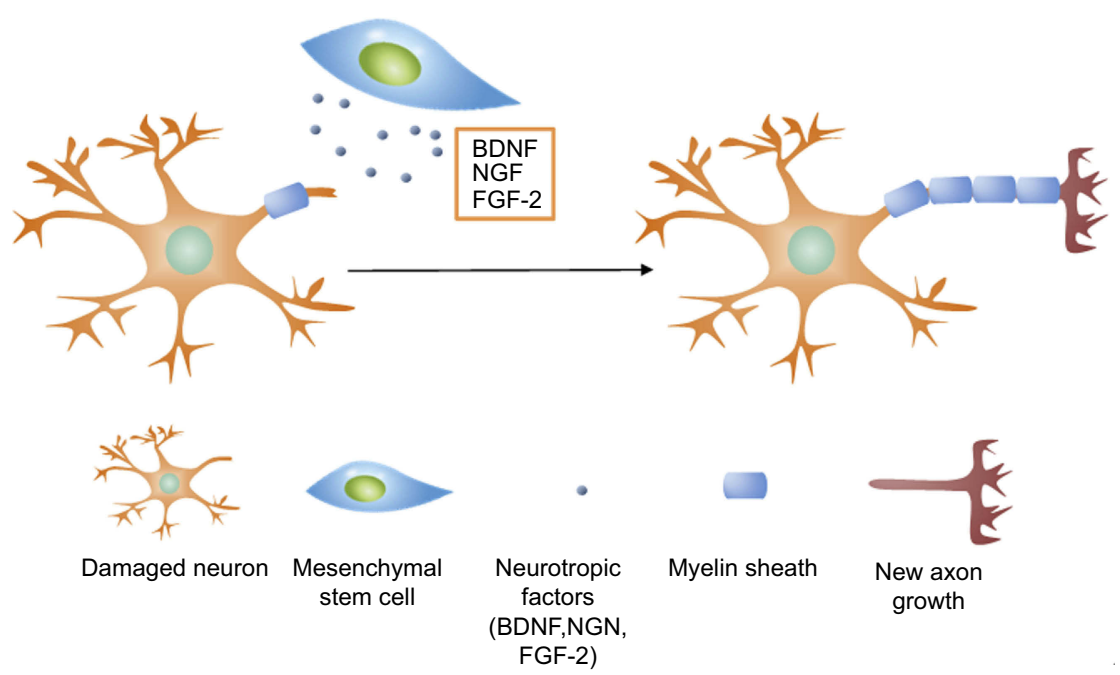

Figure 8 The mechanism of nerve regeneration assisted by mesenchymal stem cells. Neurotrophic factors including BDNF, NGF, and FGF-2 released by MSCs interact with damaged axons and induce axonal outgrowth.

\section{Enhanced nerve regeneration by nanodrug-assisted MSC}

Neurogenesis is particularly important to compensate for neurodegenerative disease, but natural neurogenesis in the central nervous system is limited due to growth inhibition by glial scar and adult myelin. ${ }^{168}$ As of today, various growth factors, extracellular matrix degrading enzymes, myelin neutralization have been reported to increase neural growth, but their usages are limited due to their low BBB perviousness. ${ }^{162,169}$ Therefore, various studies have explored bioactive molecules-loaded nanoparticles for improving neurogenesis in neurodegenerative models. For instance, curcuminloaded poly(lactic-co-glycolic acid) nanoparticles induce proliferation of NSCs in vitro through the activation of Wnt/ $\beta$-Catenin signal pathways. ${ }^{170}$ BDNF-loaded silica nanoparticles support the survival of spiral ganglion neurons in vitro. ${ }^{171}$ Likewise, iron oxide nanoparticlesconjugated NGF, glial cell-derived neurotrophic factor, and basic FGF-2 are not only stable but also show improved nerve regeneration compared to free neurotrophic factors on organotypic dorsal root ganglion. In in vivo studies, bilaterally injected silica-DNA complex successfully triggered neurogenesis of neuronal stem/ progenitor cells via stimulation of FGF Receptor 1 signaling pathway. ${ }^{172}$ However, again, the primary method of nanoparticle delivery is via local injection due to low BBB permeability. The major drawback of local injection is loss of nanoparticles due to backflow of the solution. ${ }^{173}$
Based on previous studies, it is anticipated that utilizing MSCs as cargo molecule can pave a way for safe delivery of neurotrophic factors loaded nanoparticles to target sites for nerve regeneration. In addition, the combined efficacy of MSCs and neurotrophic factors including myelin neutralization and degrading ECM enzyme can synergistically improve axon growth.

\section{Therapeutic usage of MSC-derived secretomes}

MSCs can promote nerve regeneration by releasing specific cytokines or secretomes to the damaged nerve environment. The types of secretomes released from MSCs differ from the MSC lineages and pre-conditioning of MSCs with factors including hypoxia, inflammatory cytokines, and 3D culture. ${ }^{174,175,176}$ For instance, adipose-derived mesenchymal stem cells induced higher expressions of IGF-1 and IL8 , but bone marrow-derived mesenchymal stem cells triggered significant expressions of IL-6, IL-8, IL-1 $\alpha$, and IL$1 \beta$ without any pre-conditioning treatment. ${ }^{177}$ In induced hypoxia condition, MSCs can secrete growth factors and pro-angiogenic cytokines such as VEGF and IGF-1. ${ }^{162}$ Likewise, conditioned medium of bone marrow-derived stem cell inhibits apoptosis and promotes VEGF-involving pro-angiogenic activity of neurons to support neuronal survivability in in vitro study. ${ }^{178}$ Utilizing MSCs secretomes can provide many advantages in terms of storage, economical cost, and modification, but the clinical application of only-secretome treatment for therapeutic use remains 
challenging due to poor protein stability, pharmacokinetics, and tissue transport. ${ }^{179,180}$

\section{Discussion and perspective}

Despite technological developments in antitumor therapeutics, the majority of chemotherapeutics is precluded from entering the brain due to the presence of the BBB. Moreover, the BBB can efflux undesired molecules from the brain even if they enter the brain. Thus, GBM is widely known as one of the most devastating diseases without well-defined solutions. Conventional chemotherapies for GBM are accompanied with adverse side effects, worsening the quality of patients' lives. Treatment for GBM is problematic since its heterogeneous structure and overexpression of its corresponding genes makes it resistant to not only chemotherapy but also radiotherapy. Therefore, studies developing new chemotherapies have been extensively investigating methods to improve tumor-migration and BBB-perviousness of a drug.

Although genetic alternation of MSCs showed the promising results, intact MSCs can hold similar therapeutic efficiency by loading various therapeutic agents and can reduce potential tumorigenesis from genetic alternation. This review introduces non-genetically modified MSCs as a new strategy in overcoming this hurdle given the unique features of MSCs in tumor inhibition and tropism, and highlights that MSCs loaded with chemotherapeutics can efficiently deliver the loaded chemotherapeutic agents to tumor sites. Furthermore, as the chemotherapeutic agent is delivered to tumor sites, MSCs can induce apoptosis and inhibit angiogenesis of tumor cells, synergistically eradicating glioma cells.

The nervous system of patients after either completion of surgical or chemotherapeutic treatment is severely damaged, and neurogenesis is rarely induced naturally. The ability to artificially promote nerve regeneration through the anti-inflammation effect achieved via release of anti-inflammatory cytokines from MSCs and nerve regeneration-promoting nanodrug, nanoparticle-loaded MSCs is a promising treatment that can regenerate damaged nerve system. Although secretomes or cytokines released from MSCs can alone induce pro-survival of neurons, poor stabilities and pharmacokinetics of secretomes in physiological conditions limit the usage of secretomes. On the other hand, MSCs can efficiently deliver adjuvant drug-loaded nanoparticles to inflammation sites for anti-inflammation and neuroregeneration after complete removal of tumor cells. Furthermore, MSCs at inflammation sites can mediate inflammations by secreting desired secretomes to activate M2 macrophages.
In conclusion, this review discusses the potential clinical application of nanocarrier-assisted MSCs as not only antitumor agents through improved tumor specificity and apoptosis but also regenerative and anti-inflammatory agents through neurogenesis factor delivery and MSCreleased secretomes. Since some pathways inducing neurogenesis promote tumor progression as well, great care should be taken to ensure that treatment of damaged neural tissue is done after the complete eradication of tumor. The distinctive abilities of MSCs with the assist of nanotechnology introduced in this review can pave the way for new guidelines on antitumor and nerve regenerative therapy with promising results in the near future and overcome the limitation of genetically engineered MSCs.

\section{Acknowledgment}

This research was supported by grants from Gachon University of Funds (2017-0180) and Gil Medical Center Research Fund (2018-5295).

\section{Disclosure}

The authors state that there are no conflicts of interest in this work.

\section{References}

1. Oike T, Suzuki Y, Sugawara K, et al. Radiotherapy plus concomitant adjuvant temozolomide for glioblastoma: Japanese mono-institutional results. PLoS One. 2013;8(11):e78943. doi:10.1371/ journal.pone. 0078943

2. Yuan X, Curtin J, Xiong Y, et al. Isolation of cancer stem cells from adult glioblastoma multiforme. Oncogene. 2004;23(58):93929400. doi:10.1038/sj.onc. 1208311

3. Sminia P, Westerman BA. Blood-brain barrier crossing and breakthroughs in glioblastoma therapy. Br J Clin Pharmacol. 2016;81 (6):1018-1020. doi:10.1111/bcp.12881

4. Anjum K, Shagufta BI, Abbas SQ, et al. Current status and future therapeutic perspectives of glioblastoma multiforme (GBM) therapy: a review. Biomed Pharmacother. 2017;92:681-689. doi:10.1016/j.biopha.2017.05.125

5. Upadhyay RK. Drug delivery systems, CNS protection, and the blood brain barrier. Biomed Res Int. 2014;2014:869269. doi:10.1155/2014/869269

6. Liang XJ, Chen C, Zhao Y, Wang PC. Circumventing tumor resistance to chemotherapy by nanotechnology. Methods Mol Biol. 2010;596:467-488. doi:10.1007/978-1-60761-416-6_21

7. Dong X. Current strategies for brain drug delivery. Theranostics. 2018;8(6):1481-1493. doi:10.7150/thno.21254

8. Kim N, Cho SG. Clinical applications of mesenchymal stem cells. Korean J Intern Med. 2013;28(4):387-402. doi:10.3904/ kjim.2013.28.4.387

9. Wei X, Yang X, Han ZP, Qu FF, Shao L, Shi YF. Mesenchymal stem cells: a new trend for cell therapy. Acta Pharmacol Sin. 2013;34(6):747-754.

10. Kumar S, Chanda D, Ponnazhagan S. Therapeutic potential of genetically modified mesenchymal stem cells. Gene Ther. 2008;15(10):711-715. doi:10.1038/gt.2008.35 
11. Awad HA, Butler DL, Boivin GP, et al. Autologous mesenchymal stem cell-mediated repair of tendon. Tissue Eng. 1999;5(3):267277. doi:10.1089/ten.1999.5.267

12. Shi S, Bartold PM, Miura M, Seo BM, Robey PG, Gronthos S. The efficacy of mesenchymal stem cells to regenerate and repair dental structures. Orthod Craniofac Res. 2005;8(3):191-199. doi:10.1111/ j.1601-6343.2005.00331.x

13. Aleynik A, Gernavage KM, Mourad Y, et al. Stem cell delivery of therapies for brain disorders. Clin Transl Med. 2014;3:24. doi:10.1186/2001-1326-3-24

14. Dimarino AM, Caplan AI, Bonfield TL. Mesenchymal stem cells in tissue repair. Front Immunol. 2013;4:201. doi:10.3389/ fimmu.2013.00201

15. Matsushita T, Kibayashi T, Katayama T, et al. Mesenchymal stem cells transmigrate across brain microvascular endothelial cell monolayers through transiently formed inter-endothelial gaps. Neurosci Lett. 2011;502(1):41-45. doi:10.1016/j.neulet.2011.07.021

16. Kallmeyer K, Pepper MS. Homing properties of mesenchymal stromal cells. Expert Opin Biol Ther. 2015;15(4):477-479.

17. Khatab S, van Osch GJ, Kops N, et al. Mesenchymal stem cell secretome reduces pain and prevents cartilage damage in a murine osteoarthritis model. Eur Cell Mater. 2018;36:218-230. doi:10.22203/eCM.v036a16

18. Secunda R, Vennila R, Mohanashankar AM, Rajasundari M, Jeswanth $\mathrm{S}$, Surendran R. Isolation, expansion and characterisation of mesenchymal stem cells from human bone marrow, adipose tissue, umbilical cord blood and matrix: a comparative study. Cytotechnology. 2015;67 (5):793-807. doi:10.1007/s10616-014-9718-z

19. Beyer Nardi N, da Silva Meirelles L. Mesenchymal stem cells: isolation, in vitro expansion and characterization. Handb Exp Pharmacol. 2006;(174):249-282.

20. Su P, Tian Y, Yang C, et al. Mesenchymal stem cell migration during bone formation and bone diseases therapy. Int J Mol Sci. 2018;19:8. doi:10.3390/ijms19082343

21. Huang X, Zhang F, Wang H, et al. Mesenchymal stem cell-based cell engineering with multifunctional mesoporous silica nanoparticles for tumor delivery. Biomaterials. 2013;34(7):1772-1780. doi:10.1016/j.biomaterials.2012.11.032

22. Li L, Guan Y, Liu H, et al. Silica nanorattle-doxorubicin-anchored mesenchymal stem cells for tumor-tropic therapy. ACS Nano. 2011;5(9):7462-7470.

23. Kalber TL, Ordidge KL, Southern P, et al. Hyperthermia treatment of tumors by mesenchymal stem cell-delivered superparamagnetic iron oxide nanoparticles. Int J Nanomedicine. 2016;11:1973-1983. doi:10.2147/IJN.S94255

24. Kim SW, Lee YK, Hong JH, et al. Mutual destruction of deep lung tumor tissues by nanodrug-conjugated stealth mesenchymal stem cells. Adv Sci (Weinh). 2018;5(5):1700860. doi:10.1002/ advs. 201700860

25. Li SD, Huang L. Non-viral is superior to viral gene delivery. J Control Release. 2007;123(3):181-183. doi:10.1016/j.jconrel.2007.09.004

26. Peer D, Karp JM, Hong S, Farokhzad OC, Margalit R, Langer R. Nanocarriers as an emerging platform for cancer therapy. Nat Nanotechnol. 2007;2(12):751-760.

27. Johannsen M, Thiesen B, Wust P, Jordan A. Magnetic nanoparticle hyperthermia for prostate cancer. Int J Hyperthermia. 2010;26 (8):790-795. doi:10.3109/02656731003745740

28. Khdair A, Chen D, Patil Y, et al. Nanoparticle-mediated combination chemotherapy and photodynamic therapy overcomes tumor drug resistance. J Control Release. 2010;141(2):137-144. doi:10.1016/j.jconrel.2009.09.004

29. Hainfeld JF, Lin L, Slatkin DN, Avraham Dilmanian F, Vadas TM, Smilowitz HM. Gold nanoparticle hyperthermia reduces radiotherapy dose. Nanomedicine. 2014;10(8):1609-1617. doi:10.1016/j. nano.2014.05.006
30. Ferrari M. Cancer nanotechnology: opportunities and challenges. Nat Rev Cancer. 2005;5(3):161-171. doi:10.1038/nrc1566

31. Li X, Wei Z, Lv H, et al. Iron oxide nanoparticles promote the migration of mesenchymal stem cells to injury sites. Int $J$ Nanomedicine. 2019;14:573-589. doi:10.2147/IJN.S184920

32. Huang X, Zhang F, Wang Y, et al. Design considerations of iron-based nanoclusters for noninvasive tracking of mesenchymal stem cell homing. ACS Nano. 2014;8(5):4403-4414. doi:10.1021/nn4062726

33. Wang X, Gao J, Ouyang X, Wang J, Sun X, Lv Y. Mesenchymal stem cells loaded with paclitaxel-poly(lactic-co-glycolic acid) nanoparticles for glioma-targeting therapy. Int $J$ Nanomedicine. 2018;13:5231-5248. doi:10.2147/IJN.S167142

34. Sweeney MD, Sagare AP, Zlokovic BV. Blood-brain barrier breakdown in Alzheimer disease and other neurodegenerative disorders. Nat Rev Neurol. 2018;14(3):133-150. doi:10.1038/nrneurol.2017.188

35. Armulik A, Genove G, Mae M, et al. Pericytes regulate the blood-brain barrier. Nature. 2010;468(7323):557-561. doi:10.1038/nature09522

36. Abbott NJ. Astrocyte-endothelial interactions and blood-brain barrier permeability. J Anat. 2002;200(6):629-638. doi:10.1046/ j.1469-7580.2002.00064.x

37. Abbott NJ, Patabendige AA, Dolman DE, Yusof SR, Begley DJ. Structure and function of the blood-brain barrier. Neurobiol Dis. 2010;37(1):13-25. doi:10.1016/j.nbd.2009.07.030

38. Pardridge WM. Alzheimer's disease drug development and the problem of the blood-brain barrier. Alzheimers Dement. 2009;5 (5):427-432. doi:10.1016/j.jalz.2009.06.003

39. Begley DJ. ABC transporters and the blood-brain barrier. Curr Pharm Des. 2004;10(12):1295-1312.

40. Habgood MD, Bye N, Dziegielewska KM, et al. Changes in bloodbrain barrier permeability to large and small molecules following traumatic brain injury in mice. Eur J Neurosci. 2007;25(1):231238. doi:10.1111/j.1460-9568.2006.05275.x

41. van Tellingen $\mathrm{O}$, Yetkin-Arik B, de Gooijer MC, Wesseling P, Wurdinger T, de Vries HE. Overcoming the blood-brain tumor barrier for effective glioblastoma treatment. Drug Resist Updat. 2015;19:1-12. doi:10.1016/j.drup.2015.02.002

42. Groothuis DR. The blood-brain and blood-tumor barriers: a review of strategies for increasing drug delivery. Neuro Oncol. 2000;2 (1):45-59. doi:10.1093/neuonc/2.1.45

43. Kang JH, Cho J, Ko YT. Investigation on the effect of nanoparticle size on the blood-brain tumour barrier permeability by in situ perfusion via internal carotid artery in mice. J Drug Target. 2019;27(1):103-110. doi:10.1080/1061186X.2018.1497037

44. Alifieris C, Trafalis DT. Glioblastoma multiforme: pathogenesis and treatment. Pharmacol Ther. 2015;152:63-82. doi:10.1016/j. pharmthera.2015.05.005

45. Haar CP, Hebbar P, GCt W, et al. Drug resistance in glioblastoma: a mini review. Neurochem Res. 2012;37(6):1192-1200. doi:10.1007/ s11064-011-0701-1

46. Mukherjee B, McEllin B, Camacho CV, et al. EGFRvIII and DNA double-strand break repair: a molecular mechanism for radioresistance in glioblastoma. Cancer Res. 2009;69(10):4252-4259. doi:10.1158/0008-5472.CAN-08-4853

47. Wen PY, Kesari S. Malignant gliomas in adults. $N$ Engl J Med. 2008;359(5):492-507. doi:10.1056/NEJMra0708126

48. Touat M, Idbaih A, Sanson M, Ligon KL. Glioblastoma targeted therapy: updated approaches from recent biological insights. Ann Oncol. 2017;28(7):1457-1472. doi:10.1093/annonc/mdx106

49. Ku MC, Waiczies S, Niendorf T, Pohlmann A. Assessment of blood brain barrier leakage with gadolinium-enhanced MRI. Methods $\mathrm{Mol}$ Biol. 2018;1718:395-408. doi:10.1007/978-1-4939-7531-0_23

50. Ryu JK, McLarnon JG. A leaky blood-brain barrier, fibrinogen infiltration and microglial reactivity in inflamed Alzheimer's disease brain. J Cell Mol Med. 2009;13(9A):2911-2925. doi:10.1111/ j.1582-4934.2008.00434.x 
51. Obermeier B, Daneman R, Ransohoff RM. Development, maintenance and disruption of the blood-brain barrier. Nat Med. 2013;19 (12):1584-1596. doi:10.1038/nm.3407

52. Schneider SW, Ludwig T, Tatenhorst L, et al. Glioblastoma cells release factors that disrupt blood-brain barrier features. Acta Neuropathol. 2004;107(3):272-276. doi:10.1007/s00401-003-0810-2

53. Dubois LG, Campanati L, Righy C, et al. Gliomas and the vascular fragility of the blood brain barrier. Front Cell Neurosci. 2014;8:418. doi:10.3389/fncel.2014.00052

54. Minniti G, Muni R, Lanzetta G, Marchetti P, Enrici RM. Chemotherapy for glioblastoma: current treatment and future perspectives for cytotoxic and targeted agents. Anticancer Res. 2009;29(12):5171-5184.

55. Kim SS, Harford JB, Pirollo KF, Chang EH. Effective treatment of glioblastoma requires crossing the blood-brain barrier and targeting tumors including cancer stem cells: the promise of nanomedicine. Biochem Biophys Res Commun. 2015;468(3):485-489. doi:10.1016/j.bbrc.2015.06.137

56. Kuhnt D, Becker A, Ganslandt O, Bauer M, Buchfelder M, Nimsky C. Correlation of the extent of tumor volume resection and patient survival in surgery of glioblastoma multiforme with high-field intraoperative MRI guidance. Neuro Oncol. 2011;13(12):13391348. doi:10.1093/neuonc/nor133

57. Montano N, Cenci T, Martini M, et al. Expression of EGFRvIII in glioblastoma: prognostic significance revisited. Neoplasia. 2011;13 (12):1113-1121. doi:10.1593/neo.111338

58. Oshiro S, Tsugu H, Komatsu F, et al. Efficacy of temozolomide treatment in patients with high-grade glioma. Anticancer Res. 2009;29(3):911-917.

59. Lee SY. Temozolomide resistance in glioblastoma multiforme. Genes Dis. 2016;3(3):198-210. doi:10.1016/j.gendis.2016.04.007

60. Sun YL, Patel A, Kumar P, Chen ZS. Role of ABC transporters in cancer chemotherapy. Chin J Cancer. 2012;31(2):51-57. doi:10.5732/cjc.011.10466

61. Bagley SJ, Desai AS, Linette GP, June CH, O'Rourke DM. CAR Tcell therapy for glioblastoma: recent clinical advances and future challenges. Neuro Oncol. 2018;20(11):1429-1438.

62. Chuntova P, Downey KM, Hegde B, Almeida ND, Okada H. Genetically engineered T-Cells for malignant glioma: overcoming the barriers to effective immunotherapy. Front Immunol. 2018;9:3062. doi:10.3389/fimmu.2018.03062

63. Egea V, von Baumgarten L, Schichor C, et al. TNF-alpha respecifies human mesenchymal stem cells to a neural fate and promotes migration toward experimental glioma. Cell Death Differ. 2011;18 (5):853-863. doi:10.1038/cdd.2010.154

64. Spees JL, Lee RH, Gregory CA. Mechanisms of mesenchymal stem/stromal cell function. Stem Cell Res Ther. 2016;7(1):125 doi:10.1186/s13287-016-0363-7

65. Lourenco S, Teixeira VH, Kalber T, Jose RJ, Floto RA, Janes SM. Macrophage migration inhibitory factor-CXCR4 is the dominant chemotactic axis in human mesenchymal stem cell recruitment to tumors. J Immunol. 2015;194(7):3463-3474. doi:10.4049/jimmunol.1402097

66. Kalimuthu S, Zhu L, Oh JM, et al. Migration of mesenchymal stem cells to tumor xenograft models and in vitro drug delivery by doxorubicin. Int J Med Sci. 2018;15(10):1051-1061. doi:10.7150/ ijms. 25760

67. Papaccio F, Paino F, Regad T, Papaccio G, Desiderio V, Tirino V. Concise review: cancer cells, cancer stem cells, and mesenchymal stem cells: influence in cancer development. Stem Cells Transl Med. 2017;6(12):2115-2125. doi:10.1002/sctm.17-0138

68. Shah K. Mesenchymal stem cells engineered for cancer therapy. Adv Drug Deliv Rev. 2012;64(8):739-748. doi:10.1016/j. addr.2011.06.010
69. Reagan MR, Kaplan DL. Concise review: mesenchymal stem cell tumor-homing: detection methods in disease model systems. Stem Cells. 2011;29(6):920-927. doi:10.1002/stem.645

70. Ahn JO, Coh YR, Lee HW, Shin IS, Kang SK, Youn HY. Human adipose tissue-derived mesenchymal stem cells inhibit melanoma growth in vitro and in vivo. Anticancer Res. 2015;35(1):159-168.

71. Hou L, Wang X, Zhou Y, et al. Inhibitory effect and mechanism of mesenchymal stem cells on liver cancer cells. Tumour Biol. 2014;35(2):1239-1250. doi:10.1007/s13277-013-1165-5

72. Clarke MR, Imhoff FM, Baird SK. Mesenchymal stem cells inhibit breast cancer cell migration and invasion through secretion of tissue inhibitor of metalloproteinase-1 and -2. Mol Carcinog. 2015;54(10):1214-1219

73. He N, Kong Y, Lei X, et al. MSCs inhibit tumor progression and enhance radiosensitivity of breast cancer cells by down-regulating Stat3 signaling pathway. Cell Death Dis. 2018;9(10):1026. doi:10.1038/s41419-018-1111-y

74. Rhee KJ, Lee JI, Eom YW. Mesenchymal stem cell-mediated effects of tumor support or suppression. Int J Mol Sci. 2015;16 (12):30015-30033. doi:10.3390/ijms161226215

75. Melzer C, Yang Y, Hass R. Interaction of MSC with tumor cells. Cell Commun Signal. 2016;14(1):20. doi:10.1186/s12964-016-0143-0

76. Ridge SM, Sullivan FJ, Glynn SA. Mesenchymal stem cells: key players in cancer progression. Mol Cancer. 2017;16(1):31. doi:10.1186/s12943-017-0597-8

77. Marofi F, Vahedi G, Biglari A, Esmaeilzadeh A, Athari SS Mesenchymal stromal/stem cells: a new era in the cell-based targeted gene therapy of cancer. Front Immunol. 2017;8:1770. doi:10.3389/fimmu.2017.01770

78. Gomari H, Moghadam MF, Soleimani M. Targeted cancer therapy using engineered exosome as a natura drug delivery vehicle. Oncotargets Ther. 2018;11:5753-5762. doi:10.2147/OTT.S173110

79. Lu JH, Peng BY, Chang CC, et al. Tumor-targeted immunotherapy by using primary adipose-derived stem cells and an antigen-specific protein vaccine. Cancers. 2018;10:11. doi:10.3390/cancers 10110400

80. Kudo-Saito C. Cancer-associated mesenchymal stem cells aggravate tumor progression. Front Cell Dev Biol. 2015;3:23. doi:10.3389/fcell.2015.00023

81. Gomez-Cuadrado L, Tracey N, Ma R, Qian B, Brunton VG. Mouse models of metastasis: progress and prospects. Dis Model Mech. 2017;10(9):1061-1074. doi:10.1242/dmm.030403

82. Li GC, Zhang HW, Zhao QC, et al. Mesenchymal stem cells promote tumor angiogenesis via the action of transforming growth factor beta1. Oncol Lett. 2016;11(2):1089-1094. doi:10.3892/ ol.2015.3997

83. Melzer C, von der Ohe J, Hass R. Enhanced metastatic capacity of breast cancer cells after interaction and hybrid formation with mesenchymal stroma/stem cells (MSC). Cell Commun Signal. 2018;16(1):2. doi:10.1186/s12964-018-0215-4

84. Namba H, Kawaji H, Yamasaki T. Use of genetically engineered stem cells for glioma therapy (Review). Oncol Lett. 2016;11(1):9-15.

85. Wang S, Miao Z, Yang Q, Wang Y, Zhang J. The dynamic roles of mesenchymal stem cells in colon cancer. Can $J$ Gastroenterol Hepatol. 2018;2018:7628763.

86. De Becker A, Riet IV. Homing and migration of mesenchymal stromal cells: how to improve the efficacy of cell therapy? World J Stem Cells. 2016;8(3):73-87.

87. Hocking AM. The role of chemokines in mesenchymal stem cell homing to wounds. Adv Wound Care (New Rochelle). 2015;4 (11):623-630.

88. Liu H, Liu S, Li Y, et al. The role of SDF-1-CXCR4/CXCR7 axis in the therapeutic effects of hypoxia-preconditioned mesenchymal stem cells for renal ischemia/reperfusion injury. PLoS One. 2012;7 (4):e34608. 
89. Dong F, Harvey J, Finan A, Weber K, Agarwal U, Penn MS. Myocardial CXCR4 expression is required for mesenchymal stem cell mediated repair following acute myocardial infarction. Circulation. 2012;126(3):314-324.

90. Karp JM, Leng Teo GS. Mesenchymal stem cell homing: the devil is in the details. Cell Stem Cell. 2009;4(3):206-216.

91. Nitzsche F, Muller C, Lukomska B, Jolkkonen J, Deten A, Boltze J. Concise review:MSC adhesion cascade-insights into homing and transendothelial migration. Stem Cells. 2017;35(6):1446-1460.

92. Zachar L, Bacenkova D, Rosocha J. Activation, homing, and role of the mesenchymal stem cells in the inflammatory environment. $J$ Inflamm Res. 2016;9:231-240.

93. Lin W, Xu L, Zwingenberger S, Gibon E, Goodman SB, Li G. Mesenchymal stem cells homing to improve bone healing. $J$ Orthop Translat. 2017;9:19-27.

94. Roberts TK, Buckner CM, Berman JW. Leukocyte transmigration across the blood-brain barrier: perspectives on neuroAIDS. Front Biosci (Landmark Ed). 2010;15:478-536.

95. Muller WA. The regulation of transendothelial migration: new knowledge and new questions. Cardiovasc Res. 2015;107(3):310320.

96. Vestweber D. How leukocytes cross the vascular endothelium. Nat Rev Immunol. 2015;15(11):692-704.

97. Teo GS, Ankrum JA, Martinelli R, et al. Mesenchymal stem cells transmigrate between and directly through tumor necrosis factoralpha-activated endothelial cells via both leukocyte-like and novel mechanisms. Stem Cells. 2012;30(11):2472-2486.

98. Lu YR, Yuan Y, Wang XJ, et al. The growth inhibitory effect of mesenchymal stem cells on tumor cells in vitro and in vivo. Cancer Biol Ther. 2008;7(2):245-251.

99. Dasari VR, Velpula KK, Kaur K, et al. Cord blood stem cell-mediated induction of apoptosis in glioma downregulates X-linked inhibitor of apoptosis protein (XIAP). PLoS One. 2010;5(7):e11813.

100. Yang C, Lei D, Ouyang W, et al. Conditioned media from human adipose tissue-derived mesenchymal stem cells and umbilical cord-derived mesenchymal stem cells efficiently induced the apoptosis and differentiation in human glioma cell lines in vitro. Biomed Res Int. 2014;2014:109389. doi:10.1155/2014/ 109389

101. Jiang X, Fitch S, Wang C, et al. Nanoparticle engineered TRAILoverexpressing adipose-derived stem cells target and eradicate glioblastoma via intracranial delivery. Proc Natl Acad Sci U S A. 2016;113(48):13857-13862. doi:10.1073/pnas.1615396113

102. Grisendi G, Spano C, D'Souza N, et al. Mesenchymal progenitors expressing TRAIL induce apoptosis in sarcomas. Stem Cells. 2015;33(3):859-869. doi:10.1002/stem.1903

103. Villars F, Guillotin B, Amedee T, et al. Effect of HUVEC on human osteoprogenitor cell differentiation needs heterotypic gap junction communication. Am J Physiol Cell Physiol. 2002;282(4): C775-C785. doi:10.1152/ajpcell.00310.2001

104. Otsu K, Das S, Houser SD, Quadri SK, Bhattacharya S, Bhattacharya J. Concentration-dependent inhibition of angiogenesis by mesenchymal stem cells. Blood. 2009;113(18):4197-4205. doi:10.1182/blood-2008-09-176198

105. Pacioni S, D'Alessandris QG, Giannetti S, et al. Human mesenchymal stromal cells inhibit tumor growth in orthotopic glioblastoma xenografts. Stem Cell Res Ther. 2017;8(1):53. doi:10.1186/s13287017-0601-7

106. Ho IA, Toh $\mathrm{HC}, \mathrm{Ng} \mathrm{WH}$, et al. Human bone marrow-derived mesenchymal stem cells suppress human glioma growth through inhibition of angiogenesis. Stem Cells. 2013;31(1):146-155. doi:10.1002/stem.1247

107. Krueger TE, Thorek DLJ, Meeker AK, Isaacs JT, Brennen WN. Tumor-infiltrating mesenchymal stem cells: drivers of the immunosuppressive tumor microenvironment in prostate cancer? Prostate. 2019;79(3):320-330. doi:10.1002/pros.23738
108. Kidd S, Spaeth E, Dembinski JL, et al. Direct evidence of mesenchymal stem cell tropism for tumor and wounding microenvironments using in vivo bioluminescent imaging. Stem Cells. 2009;27(10):2614-2623. doi:10.1002/stem.187

109. Li M, Zhang F, Chen K, et al. Nanoparticles and mesenchymal stem cells: a win-win alliance for anticancer drug delivery. $R S C$ Adv. 2016;6(43):36910-36922. doi:10.1039/C6RA00398B

110. Wu J, Liu Y, Tang Y, et al. Synergistic chemo-photothermal therapy of breast cancer by mesenchymal stem cell-encapsulated yolk-shell GNR@HPMO-PTX nanospheres. ACS Appl Mater Interfaces. 2016;8(28):17927-17935. doi:10.1021/acsami.6b05677

111. Encabo-Berzosa MM, Gimeno M, Lujan L, et al. Selective delivery of photothermal nanoparticles to tumors using mesenchymal stem cells as Trojan horses. RSC Adv. 2016;6(63):58723-58732. doi:10.1039/C6RA10058A

112. Kang S, Bhang SH, Hwang S, et al. Mesenchymal stem cells aggregate and deliver gold nanoparticles to tumors for photothermal therapy. ACS Nano. 2015;9(10):9678-9690. doi:10.1021/ acsnano. 5 b02207

113. Roger M, Clavreul A, Venier-Julienne MC, et al. Mesenchymal stem cells as cellular vehicles for delivery of nanoparticles to brain tumors. Biomaterials. 2010;31(32):8393-8401. doi:10.1016/j. biomaterials.2010.07.048

114. Marelli G, Howells A, Lemoine NR, Wang Y. Oncolytic viral therapy and the immune system: a double-edged sword against cancer. Front Immunol. 2018;9:866. doi:10.3389/fimmu.2018. 00866

115. Kaufman HL, Kohlhapp FJ, Zloza A. Oncolytic viruses: a new class of immunotherapy drugs. Nat Rev Drug Discov. 2015;14 (9):642-662. doi:10.1038/nrd4663

116. Parker Kerrigan BC, Shimizu Y, Andreeff M, Lang FF. Mesenchymal stromal cells for the delivery of oncolytic viruses in gliomas. Cytotherapy. 2017;19(4):445-457. doi:10.1016/j. jcyt.2017.02.002

117. Ferguson MS, Lemoine NR, Wang Y. Systemic delivery of oncolytic viruses: hopes and hurdles. Adv Virol. 2012;2012:805629. doi:10.1155/2012/805629

118. Sonabend AM, Ulasov IV, Tyler MA, Rivera AA, Mathis JM, Lesniak MS. Mesenchymal stem cells effectively deliver an oncolytic adenovirus to intracranial glioma. Stem Cells. 2008;26 (3):831-841. doi:10.1634/stemcells.2007-0758

119. Ahmed AU, Rolle CE, Tyler MA, et al. Bone marrow mesenchymal stem cells loaded with an oncolytic adenovirus suppress the anti-adenoviral immune response in the cotton rat model. Mol Ther. 2010;18(10):1846-1856. doi:10.1038/mt.2010.131

120. Xu G, Jiang XD, Xu Y, et al. Adenoviral-mediated interleukin-18 expression in mesenchymal stem cells effectively suppresses the growth of glioma in rats. Cell Biol Int. 2009;33(4):466-474. doi:10.1016/j.cellbi.2008.07.023

121. Gunnarsson S, Bexell D, Svensson A, Siesjo P, Darabi A, Bengzon J. Intratumoral IL-7 delivery by mesenchymal stromal cells potentiates IFNgamma-transduced tumor cell immunotherapy of experimental glioma. J Neuroimmunol. 2010;218(12):140-144. doi:10.1016/j.jneuroim.2009.10.017

122. van Eekelen M, Sasportas LS, Kasmieh R, et al. Human stem cells expressing novel TSP-1 variant have anti-angiogenic effect on brain tumors. Oncogene. 2010;29(22):3185-3195. doi:10.1038/ onc. 2010.75

123. Kim SM, Lim JY, Park SI, et al. Gene therapy using TRAILsecreting human umbilical cord blood-derived mesenchymal stem cells against intracranial glioma. Cancer Res. 2008;68(23):96149623. doi:10.1158/0008-5472.CAN-08-0451

124. Sasportas LS, Kasmieh R, Wakimoto H, et al. Assessment of therapeutic efficacy and fate of engineered human mesenchymal stem cells for cancer therapy. Proc Natl Acad Sci U S A. 2009;106 (12):4822-4827. doi:10.1073/pnas.0806647106 
125. Hong X, Miller C, Savant-Bhonsale S, Kalkanis SN. Antitumor treatment using interleukin-12-secreting marrow stromal cells in an invasive glioma model. Neurosurgery. 2009;64(6):1139-1146. discussion 1146-1137. doi:10.1227/01.NEU.0000345646.85472.EA

126. Ryu CH, Park KY, Kim SM, et al. Valproic acid enhances antitumor effect of mesenchymal stem cell mediated HSV-TK gene therapy in intracranial glioma. Biochem Biophys Res Commun. 2012;421(3):585-590. doi:10.1016/j.bbrc.2012.04.050

127. Yao S, Li X, Liu J, Sun Y, Wang Z, Jiang Y. Maximized nanodrugloaded mesenchymal stem cells by a dual drug-loaded mode for the systemic treatment of metastatic lung cancer. Drug Deliv. 2017;24 (1):1372-1383. doi:10.1080/10717544.2017.1375580

128. Lee C, Hwang HS, Lee S, et al. Rabies virus-inspired silica-coated gold nanorods as a photothermal therapeutic platform for treating brain tumors. Adv Mater. 2017;29:13. doi:10.1002/adma.201700681

129. Kim SM, Woo JS, Jeong CH, Ryu CH, Lim JY, Jeun SS. Effective combination therapy for malignant glioma with TRAIL-secreting mesenchymal stem cells and lipoxygenase inhibitor MK886. Cancer Res. 2012;72(18):4807-4817. doi:10.1158/0008-5472. CAN-12-0123

130. Ahmed AU, Tyler MA, Thaci B, et al. A comparative study of neural and mesenchymal stem cell-based carriers for oncolytic adenovirus in a model of malignant glioma. Mol Pharm. 2011;8 (5):1559-1572. doi:10.1021/mp200161f

131. Egawa N, Lok J, Washida K, Arai K. Mechanisms of axonal damage and repair after central nervous system injury. Transl Stroke Res. 2017;8(1):14-21. doi:10.1007/s12975-016-0495-1

132. Puentes F, Malaspina A, van Noort JM, Amor S. Non-neuronal cells in ALS: role of glial, immune cells and blood-CNS barriers. Brain Pathol. 2016;26(2):248-257. doi:10.1111/bpa.12352

133. Rolls A, Shechter R, Schwartz M. The bright side of the glial scar in CNS repair. Nat Rev Neurosci. 2009;10(3):235-241. doi:10.1038/nrn2591

134. Moeendarbary E, Weber IP, Sheridan GK, et al. The soft mechanical signature of glial scars in the central nervous system. Nat Commun. 2017;8:14787. doi:10.1038/ncomms14787

135. Geoffroy CG, Zheng B. Myelin-associated inhibitors in axonal growth after CNS injury. Curr Opin Neurobiol. 2014;27:31-38. doi:10.1016/j.conb.2014.02.012

136. Chen G, Park CK, Xie RG, Ji RR. Intrathecal bone marrow stromal cells inhibit neuropathic pain via TGF-beta secretion. J Clin Invest. 2015;125(8):3226-3240. doi:10.1172/JCI80883

137. Aras S, Zaidi MR. TAMeless traitors: macrophages in cancer progression and metastasis. Br J Cancer. 2017;117(11):15831591. doi:10.1038/bjc.2017.356

138. Chanmee T, Ontong P, Konno K, Itano N. Tumor-associated macrophages as major players in the tumor microenvironment. Cancers (Basel). 2014;6(3):1670-1690. doi:10.3390/cancers6031670

139. Biswas SK, Mantovani A. Macrophage plasticity and interaction with lymphocyte subsets: cancer as a paradigm. Nat Immunol. 2010;11(10):889-896. doi:10.1038/ni.1937

140. Qi L, Yu H, Zhang Y, et al. IL-10 secreted by M2 macrophage promoted tumorigenesis through interaction with JAK2 in glioma. Oncotarget. 2016;7(44):71673-71685. doi:10.18632/oncotarget. 12317

141. Dennis KL, Blatner NR, Gounari F, Khazaie K. Current status of interleukin-10 and regulatory T-cells in cancer. Curr Opin Oncol. 2013;25(6):637-645. doi:10.1097/CCO.0000000000000006

142. Mantovani A, Marchesi F, Malesci A, Laghi L, Allavena P. Tumourassociated macrophages as treatment targets in oncology. Nat Rev Clin Oncol. 2017;14(7):399-416. doi:10.1038/nrclinonc.2016.217

143. Vasandan AB, Jahnavi S, Shashank C, Prasad P, Kumar A, Prasanna SJ. Human Mesenchymal stem cells program macrophage plasticity by altering their metabolic status via a PGE2-dependent mechanism. Sci Rep. 2016;6:38308. doi:10.1038/srep38308
144. Saqib U, Sarkar S, Suk K, Mohammad O, Baig MS, Savai R. Phytochemicals as modulators of M1-M2 macrophages in inflammation. Oncotarget. 2018;9(25):17937-17950. doi:10.18632/ oncotarget. 24788

145. Sica A, Mantovani A. Macrophage plasticity and polarization: in vivo veritas. J Clin Invest. 2012;122(3):787-795. doi:10.1172/ JCI59643

146. Murray PJ, Wynn TA. Protective and pathogenic functions of macrophage subsets. Nat Rev Immunol. 2011;11(11):723-737. doi:10.1038/nri3073

147. Kyurkchiev D, Bochev I, Ivanova-Todorova E, et al. Secretion of immunoregulatory cytokines by mesenchymal stem cells. World $J$ Stem Cells. 2014;6(5):552-570. doi:10.4252/wjsc.v6.i5.552

148. Bernardo ME, Fibbe WE. Mesenchymal stromal cells: sensors and switchers of inflammation. Cell Stem Cell. 2013;13(4):392-402. doi:10.1016/j.stem.2013.09.006

149. Zhang QZ, Su WR, Shi SH, et al. Human gingiva-derived mesenchymal stem cells elicit polarization of $\mathrm{m} 2$ macrophages and enhance cutaneous wound healing. Stem Cells. 2010;28 (10):1856-1868. doi:10.1002/stem.503

150. Li J, Tan J, Martino MM, Lui KO. Regulatory T-Cells: potential regulator of tissue repair and regeneration. Front Immunol. 2018;9:585. doi:10.3389/fimmu.2018.00585

151. Kandasamy M, Lehner B, Kraus S, et al. TGF-beta signalling in the adult neurogenic niche promotes stem cell quiescence as well as generation of new neurons. J Cell Mol Med. 2014;18(7):14441459. doi:10.1111/jcmm. 12298

152. Azizzadeh F, Mahmoodi J, Sadigh-Eteghad S, Farajdokht F, Mohaddes G. Ghrelin exerts analgesic effects through modulation of IL-10 and TGF-beta levels in a rat model of inflammatory pain. Iran Biomed J. 2017;21(2):114-119. doi:10.18869/acadpub.ibj.21.2.114

153. Dombrowski Y, O’Hagan T, Dittmer M, et al. Regulatory T cells promote myelin regeneration in the central nervous system. Nat Neurosci. 2017;20(5):674-680. doi:10.1038/nn.4528

154. Vidal PM, Lemmens E, Dooley D, Hendrix S. The role of "antiinflammatory" cytokines in axon regeneration. Cytokine Growth Factor Rev. 2013;24(1):1-12. doi:10.1016/j.cytogfr.2012.08.008

155. Cooney DS, Wimmers EG, Ibrahim Z, et al. Mesenchymal stem cells enhance nerve regeneration in a rat sciatic nerve repair and hindlimb transplant model. Sci Rep. 2016;6:31306. doi:10.1038/ srep31306

156. Marconi S, Castiglione G, Turano E, et al. Human adipose-derived mesenchymal stem cells systemically injected promote peripheral nerve regeneration in the mouse model of sciatic crush. Tissue Eng Part A. 2012;18(11-12):1264-1272. doi:10.1089/ten TEA.2011.0491

157. Woodbury D, Schwarz EJ, Prockop DJ, Black IB. Adult rat and human bone marrow stromal cells differentiate into neurons. $J$ Neurosci Res. 2000;61(4):364-370. doi:10.1002/1097-4547 (20000815)61:4<364::AID-JNR2>3.0.CO;2-C

158. Deng WW, Obrocka M, Fischer I, Prockop DJ. In vitro differentiation of human marrow stromal cells into early progenitors of neural cells by conditions that increase intracellular cyclic AMP. Biochem Bioph Res Co. 2001;282(1):148-152. doi:10.1006/bbrc.2001.4570

159. Sanchez-Ramos J, Song S, Cardozo-Pelaez F, et al. Adult bone marrow stromal cells differentiate into neural cells in vitro. Exp Neurol. 2000;164(2):247-256. doi:10.1006/exnr.2000.7389

160. Hofstetter CP, Schwarz EJ, Hess D, et al. Marrow stromal cells form guiding strands in the injured spinal cord and promote recovery. Proc Natl Acad Sci U S A. 2002;99(4):2199-2204. doi:10.1073/pnas.042678299

161. Wislet-Gendebien S, Wautier F, Leprince P, Rogister B. Astrocytic and neuronal fate of mesenchymal stem cells expressing nestin. Brain Res Bull. 2005;68(1-2):95-102. doi:10.1016/j. brainresbull.2005.08.016 
162. Rehman J, Traktuev D, Li J, et al. Secretion of angiogenic and antiapoptotic factors by human adipose stromal cells. Circulation. 2004;109(10):1292-1298. doi:10.1161/01.CIR.0000121425.429 66.F1

163. Wei $\mathrm{X}, \mathrm{Du} \mathrm{Z}$, Zhao L, et al. IFATS collection: the conditioned media of adipose stromal cells protect against hypoxia-ischemiainduced brain damage in neonatal rats. Stem Cells. 2009;27 (2):478-488. doi:10.1634/stemcells.2008-0333

164. Tan B, Luan Z, Wei X, et al. AMP-activated kinase mediates adipose stem cell-stimulated neuritogenesis of PC12 cells. Neuroscience. 2011;181:40-47. doi:10.1016/j.neuroscience.2011. 02.038

165. Olson SD, Pollock K, Kambal A, et al. Genetically engineered mesenchymal stem cells as a proposed therapeutic for Huntington's disease. Mol Neurobiol. 2012;45(1):87-98. doi:10.1007/s12035-011-8219-8

166. Pollock K, Dahlenburg H, Nelson H, et al. Human mesenchymal stem cells genetically engineered to overexpress brain-derived neurotrophic factor improve outcomes in huntington's disease mouse models. Mol Ther. 2016;24(5):965-977. doi:10.1038/mt.2016.12

167. Joyce N, Annett G, Wirthlin L, Olson S, Bauer G, Nolta JA. Mesenchymal stem cells for the treatment of neurodegenerative disease. Regen Med. 2010;5(6):933-946. doi:10.2217/rme.10.72

168. Horner PJ, Gage FH. Regenerating the damaged central nervous system. Nature. 2000;407(6807):963-970. doi:10.1038/35039559

169. Silver J, Miller JH. Regeneration beyond the glial scar. Nat Rev Neurosci. 2004;5(2):146-156. doi:10.1038/nrn1326

170. Tiwari SK, Agarwal S, Seth B, et al. Curcumin-loaded nanoparticles potently induce adult neurogenesis and reverse cognitive deficits in Alzheimer's disease model via canonical Wnt/beta-catenin pathway. ACS Nano. 2014;8(1):76-103. doi:10.1021/nn405077y

171. Schmidt N, Schulze J, Warwas DP, et al. Long-term delivery of brainderived neurotrophic factor (BDNF) from nanoporous silica nanoparticles improves the survival of spiral ganglion neurons in vitro. PLoS One. 2018;13(3):e0194778. doi:10.1371/journal.pone.0194778
172. Stachowiak EK, Roy I, Lee YW, et al. Targeting novel integrative nuclear FGFR1 signaling by nanoparticle-mediated gene transfer stimulates neurogenesis in the adult brain. Integr Biol (Camb). 2009;1(5-6):394-403. doi:10.1039/b902617g

173. Bakker RC, van Es RJJ, Rosenberg A, et al. Intratumoral injection of radioactive holmium-166 microspheres in recurrent head and neck squamous cell carcinoma: preliminary results of first use. Nucl Med Commun. 2018;39(3):213-221. doi:10.1097/MNM.00 00000000000792

174. Tran C, Damaser MS. Stem cells as drug delivery methods: application of stem cell secretome for regeneration. Adv Drug Deliv Rev. 2015;82-83:1-11. doi:10.1016/j.addr.2014.10.007

175. Pasha Z, Wang Y, Sheikh R, Zhang D, Zhao T, Ashraf M. Preconditioning enhances cell survival and differentiation of stem cells during transplantation in infarcted myocardium. Cardiovasc Res. 2008;77(1):134-142. doi:10.1093/cvr/cvm025

176. Xu Y, Shi TP, Xu AX, Zhang L. 3D spheroid culture enhances survival and therapeutic capacities of MSCs injected into ischemic kidney. J Cell Mol Med. 2016;20(7):1203-1213. doi:10.1111/ jcmm.12651

177. Cunningham CJ, Redondo-Castro E, Allan SM. The therapeutic potential of the mesenchymal stem cell secretome in ischaemic stroke. J Cereb Blood Flow Metab. 2018;38(8):1276-1292.

178. Cantinieaux D, Quertainmont R, Blacher S, et al. Conditioned medium from bone marrow-derived mesenchymal stem cells improves recovery after spinal cord injury in rats: an original strategy to avoid cell transplantation. PLoS One. 2013;8(8): e69515. doi:10.1371/journal.pone.0069515

179. Drago D, Cossetti C, Iraci N, et al. The stem cell secretome and its role in brain repair. Biochimie. 2013;95(12):2271-2285. doi:10.1016/j.biochi.2013.06.020

180. Vizoso FJ, Eiro N, Cid S, Schneider J, Perez-Fernandez R. Mesenchymal stem cell secretome: toward cell-free therapeutic strategies in regenerative medicine. Int $J$ Mol Sci. 2017;18:9. doi:10.3390/ijms 18091852
International Journal of Nanomedicine

\section{Publish your work in this journal}

The International Journal of Nanomedicine is an international, peerreviewed journal focusing on the application of nanotechnology in diagnostics, therapeutics, and drug delivery systems throughout the biomedical field. This journal is indexed on PubMed Central, MedLine, CAS, SciSearch ${ }^{\mathbb{R}}$, Current Contents ${ }^{\mathbb{B}} /$ Clinical Medicine,
Journal Citation Reports/Science Edition, EMBase, Scopus and the Elsevier Bibliographic databases. The manuscript management system is completely online and includes a very quick and fair peer-review system, which is all easy to use. Visit http://www.dovepress.com/ testimonials.php to read real quotes from published authors. 